This item was submitted to Loughborough's Research Repository by the author.

Items in Figshare are protected by copyright, with all rights reserved, unless otherwise indicated.

\title{
Meso-scale deformation and damage in thermally bonded nonwovens
}

PLEASE CITE THE PUBLISHED VERSION

http://dx.doi.org/10.1007/s10853-012-7013-y

\section{PUBLISHER}

() Springer Science+Business Media

\section{VERSION}

SMUR (Submitted Manuscript Under Review)

\section{PUBLISHER STATEMENT}

This work is made available according to the conditions of the Creative Commons Attribution-NonCommercialNoDerivatives 4.0 International (CC BY-NC-ND 4.0) licence. Full details of this licence are available at: https://creativecommons.org/licenses/by-nc-nd/4.0/

\section{LICENCE}

CC BY-NC-ND 4.0

\section{REPOSITORY RECORD}

Farukh, Farukh, Emrah Demirci, Memis Acar, Behnam Pourdeyhimi, and Vadim V. Silberschmidt. 2019. "Meso-scale Deformation and Damage in Thermally Bonded Nonwovens". figshare.

https://hdl.handle.net/2134/17003. 


\title{
Meso-scale deformation and damage in thermally bonded nonwovens
}

\author{
*Farukh Farukh ${ }^{(a)}$, Emrah Demirci ${ }^{(a)}$, Memiş Acar ${ }^{(a)}$, Behnam Pourdeyhimi ${ }^{(b)}$, Vadim V. Silberschmidt
} (a)

a - Wolfson School of Mechanical and Manufacturing Engineering, Loughborough University, UK

b - Nonwovens Cooperative Research Center, North Carolina State University, Raleigh, NC, USA

*Corresponding author's e-mail: F.Farukh@lboro.ac.uk

Tell: +4475863680541 ; fax: +441509227585

Wolfson School of Mechanical and Manufacturing Engineering, Loughborough University, UK

\begin{abstract}
:
Thermal bonding is the fastest and cheapest technique for manufacturing nonwovens. Understanding mechanical behaviour of these materials, especially related to damage, can aid in design of products containing nonwoven parts. A finite-element model incorporating mechanical properties related to damage such as maximum stress and strain at failure of fabric's fibres would be a powerful design and optimization tool. In this study, polypropylene-based thermally bonded nonwovens manufactured at optimal processing conditions were used as a model system. A damage behaviour of the nonwoven fabric is governed by its single-fibre properties, which are obtained by conducting tensile tests over a wide range of strain rates. The fibres for the tests were extracted from the nonwoven fabric in a way that a single bond point was attached at both ends of each fibre. Additionally, similar tests were performed on unprocessed fibres, which form the nonwoven. Those experiments not only provided insight into damage mechanisms of fibres in thermally bonded nonwovens but also demonstrated a significant drop in magnitudes of failure stress and respective strain in fibres due to the bonding process. A novel technique was introduced in this study to develop damage criteria based on the deformation and fracture behaviour of a single fibre in a thermally bonded nonwoven fabric. The damage behaviour of a fibrous network within the thermally bonded fabric was simulated with a finite-element model consisting of a number of fibres attached to two neighbouring bond points. Additionally, various arrangements of fibres' orientation and material properties were implemented in the model to analyse the respective effects.
\end{abstract}

Keywords: nonwoven; polypropylene; deformation; damage; finite element 


\section{Introduction}

With increased awareness of sustainability in a modern world, thermal bonding has become the most widely used technique for manufacturing of nonwovens thanks to its low impact on environment compared to other bonding methods, e.g. chemical bonding. Furthermore, a higher production rate of nonwovens can be achieved with thermal bonding as compared to chemical and mechanical bonding processes $[1,2]$. These features, together with better control over a fibrous network, involved to attain performance characteristics tailored for a specific product, make thermally bonded nonwovens suitable for various applications. Despite their importance, information about damage initiation and propagation in thermally bonded nonwovens is very limited. Understanding the process of onset and propagation of damage and development of damage criteria for thermally bonded nonwovens can improve design of products containing nonwoven parts focussing at higher reliability and durability.

During thermal bonding, fibres are passed through hot calendar rolls with smooth or embossed surface design. Bonding occurs at raised areas of the embossed calender under pressure and high temperature by partial melting and subsequent solidification of fibres. This process results in two distinct regions, namely, bond points and a fibre matrix, as shown in Fig. 1. This bonding process affects the strength of fibres within the fabric resulting in a significantly lower fibre-failure stress threshold and strain at that stress [1-4]. Since fibres always fail near the bond-point's periphery region in thermally bonded nonwovens [4-10], therefore, it is necessary to study this region for better understanding of damage initiation and propagation in this kind of fabric. The consideration of this region in the development of damage criteria for an individual fibre within the fabric is a challenging task which is implemented by a novel experimental technique. In this technique, a tensile test of a single fibre, extracted from nonwoven in a way that a bond point is attached at its each, is performed. Damage in nonwovens occur at both micro and macro level. At micro level it occurs in fibre and at macro level in the fabric. Since, this study is based on fibre deformation and damage between the bond points, therefore, a term meso-scale is introduced for the sake of simplicity. A quantitative analysis of fibre failure within a fabric, thermally bonded at optimal temperature, can help in designing and optimising the strength of thermally bonded nonwovens. A finite-element (FE) model based on actual damage criteria and fabric microstructure would provide insights into mechanisms involved in fabric damage and enable quantitative exploration of design space for products containing thermally bonded nonwoven parts.

Several studies based on experimental and numerical modelling related to deformation and fracture of nonwovens were performed with some of them focused on micromechanisms involved in these phenomena [11-22]. Moreover, most of the work in this area was related not to nonwoven fabrics but to paper [23-26], which is a very particular type of nonwoven. To authors' knowledge, none of the work deals with the quantification of onset and propagation of damage in terms of maximum stress and corresponding strain based on experimental analysis of failure behaviour of single fibres, extracted from a fabric in a way that bond point is attached at its each end. 
The objective of this work was to develop damage criteria based on experimental data on failure stress and respective strain in thermally bonded nonwovens and implement them in a meso-scale finite-element model to understand the deformation behaviour in the studied material as well as initiation and propagation of damage in these materials.

\section{Experimental work}

\subsection{Materials}

The materials studied here were low-density $(<50 \mathrm{~g} / \mathrm{m} 2)$ thermally bonded nonwovens based on polypropylene (PP) fibres, manufactured by FibreVisions ${ }^{\circledR}$, USA. Polypropylene is the most commonly used material in the nonwovens industry due to its numerous benefits including chemical stability, good mechanical strength and low glass-transition and melting temperatures $[1,12]$. Fibre webs were manufactured using dry laid technique. Three basis weights of fabric $\left(20 \mathrm{~g} / \mathrm{m}^{2}, 30 \mathrm{~g} / \mathrm{m}^{2}, 40 \mathrm{~g} / \mathrm{m}^{2}\right)$ calendered at bonding temperature of $156^{\circ} \mathrm{C}$, which lies within the optimal temperature window for PP, were used. The microstructure of the fabric is shown in Fig. 1. Fabrics were produced with fibres of 18 $\mu \mathrm{m}$ in diameter with approximately $14 \%$ area covered by bond points.

\subsection{Fabric behaviour}

Rectangular coupons along the machine direction (MD) were cut from the nonwoven fabric to perform tensile tests at a nominal strain rate of $1 \times 10-^{2}$ s-1 using Hounsfield Benchtop Tester with pneumatic grips. A high-speed camera (Photrom Fastcam SA3) with advanced macro capabilities was used to ascertain the evolution of deformation and damage mechanisms in thermally bonded nonwovens. These tests revealed that fibres start to re-orient and straighten themselves in the loading direction immediately at the beginning of tensile deformation. Once the fibres are aligned along the loading direction, they undergo large elastic-plastic deformation and the maximum load was attained under this condition without any evidence of fibre fracture. As soon as fibres reached their stress or strain threshold, they failed resulting in localization of damage and development of fracture zones. These fracture zones were made up of the surviving straight fibres aligned along a loading direction. Further fibre failures caused a growth in fracture zones followed by the ultimate failure of the fabric. A very gradual growth of damage was observed during deformation until failure of fabric with the first and the last fibres failing at fabric extension of approximately $40 \%$ to $60 \%$ and $225 \%$ to $250 \%$, respectively (Fig. 2). Rotation of bondpoints was observed during tests without significant deformation in them. Nevertheless, it cannot be excluded from consideration that they play an important role in damage behaviour of thermally bonded nonwovens since fibres always break at the bond-point periphery. The sequence of these phenomena is shown in Fig. 3, which shows images of nonwovens at increasing levels of the overall strain. Various gauge lengths of fabric samples ranging from $5 \mathrm{~mm}$ to $15 \mathrm{~mm}$ were used in these experiments and it was 
observed that the sequence of these fabric deformation and damage intiaition as well as its propagation phenomena were same regardless to its gauge length. During deformation and damage, staggered bond points tend to come in front of each other along loading direction giving a large rotation to fibres before participating in load bearing. However, in order to study the effect of bond point arrangement on fibre failure as a function of fabric extension, two bond points in front of each other along MD were cut from the fabric and tensile tests were performed on it at a strain rate of $0.51 / \mathrm{s}$. It was observed that first and the last fibres failed at fabric extension of approximately $35 \%$ to $40 \%$ and $110 \%$ to $120 \%$, respectively, resulting in less gradual growth of damage as compared to that in fabric with staggered bond point arrangement. This reason for this phenomenon was that the fibres between two head-on bond points were aligned along loading direction earlier than that of fabric with staggered bond points. Since damage and failure of the fabric are caused by the progressive failure of fibres, therefore, it is important to develop criteria of fibre failure based on experimentation that can be used to simulate the onset of damage and its progression behaviour in thermally bonded nonwovens.

\subsection{Single-fibre specimen}

The material properties of fibres, especially their failure strength in terms of stress and strain within a thermally bonded fabric, are significantly lower than those of virgin fibres due to their thermal exposure during the bonding process [4-10, 27]. Therefore, a pragmatic approach is to use in tests individual fibres extracted from the fabric rather than unprocessed fibres in order to obtain the material properties and to develop damage criteria. Since all the fibres in thermally bonded nonwovens fail at the bond-point periphery, it is necessary to include this region into single-fibre experiments in order to develop adequate damage criteria. In order to do this, a novel experimental method is used in this study, in which fibre samples were extracted from the fabric in a way that they were attached to individual bond points at their ends (Fig. 4a). Tensile tests on such specimens would provide insights into deformation and damage of fibre within thermally bonded fabric and contribute to development of damage criteria. In order to prevent slippage, dislocation and damage of a single-fibre specimen during the test, sticky strips of paper were attached to the bond points at the edges of the fibre in such a way that only the mechanical properties of the fibre were obtained without amalgamating it with those of bonds. The schematic configuration of the specimen and its fixture are shown in Fig. $4 \mathrm{~b}$.

Those specimens were mounted on Instron ${ }^{\circledR}$ Micro Tester 5848 using peg-type grips with sticky rubber contact surfaces (Fig. 5); the complete details of specimen preparation are given in [20]. Photrom Fastcam SA3 was also used to make sure that the tested fibre was not stretched during the mounting of specimen. It also helped in monitoring the fibre to prevent its slippage during the test. The experimental setup used for our tensile testing of single-fibre is shown in Fig. 5.

The load carried by the fibre in the test was measured by a $5 \mathrm{~N}$ high-precision Instron® load cell. Fibre elongation was measured by the means of cross-head movement. Three different levels of strain rates $-0.01,0.1$ and $0.51 / \mathrm{s}$ - were used in the single-fibre tensile tests. In order to assess variability of 
the results, at least ten samples were tested for each strain rate. True strains $\left(\varepsilon_{\text {true }}\right)$ and true stresses $\left(\sigma_{\text {true }}\right)$ were recorded during the tests, which were obtained with the following relations:

$$
\begin{gathered}
\varepsilon_{\text {true }}=\int_{\mathrm{L}_{\mathrm{o}}}^{\mathrm{L}} \frac{\mathrm{dL}}{\mathrm{L}}=\ln \left(\frac{\mathrm{L}}{\mathrm{L}_{\mathrm{o}}}\right), \\
\sigma_{\text {true }}=\frac{\mathrm{F}(1+\mathrm{e})}{\mathrm{A}_{\mathrm{o}}}
\end{gathered}
$$

where $L$ and $L_{o}$ are the current and initial specimen lengths, respectively; $F$ is the load, $A_{o}$ is the initial area of fibre's cross-section and e is the engineering strain. In these calculations, it was assumed that the fibre's cross-section was perfectly circular and the diameter of fibre is constant throughout its length. True-stress and true-strain magnitudes were computed based on hypothesis that the deformation in fibre took place at constant volume. The diameter of the fibres, accurately measured with X-ray micro CT (XTEK XT-H 160Xi) device, was approximately $18 \mu \mathrm{m}$, very close to material database provided by the manufacturer. The tests with the same experimental parameters were also performed on unprocessed polypropylene fibres, used to manufacture the studied nonwoven, to quantify the effects of bonding on breaking strength of fibres.

The true stress vs. true strain curves of both processed and unprocessed PP fibres present a sigmoidal shape, which is typical for polypropylene material (Fig. 6). The experiments did not provide a certain values of failure strength and strain-at-failure; rather there was a significant scatter in results as shown in Fig 6. The average stress-strain curves with standard deviation at various strain rates for both processed and unprocessed fibres are shown in Fig. 7.

The average values with standard deviation of the failure stress $\sigma_{\mathrm{f}}$ and strain at failure $\varepsilon_{\mathrm{f}}$ are presented in Table 1. A decrease in tensile strength and strain at failure of processed fibres as compared to unprocessed ones was due to high temperature and pressure involved in the bonding process, which changes molecular orientation of fibres and thus affect failure parameters [3-7]. Hence, the material properties of unprocessed fibres are not suitable for modelling of nonwovens especially for damage analysis of the fabric. The processed single-fibre experiments provided the parameters such as material properties and damage criteria necessary for the modelling of deformation and damage behaviour of nonwovens. The predictive capability of finite element model of nonwoven was verified by the fabric uniaxial tensile tests.

\section{FE Model}

A discontinuous 3D finite element model of thermally bonded nonwoven was developed, which takes into account material's microstructure as well as deformation and failure mechanisms experimentally observed. The FE model developed in this study consisted of two distinct regions - bond points and 
fibres. In order to consider the randomness in material's microstructure, two arrangements of fibres parallel and with random orientation- were modelled between two adjacent bond points as shown in Fig. 10. The randomness of fibres' orientation is implemented in the model in terms of orientation distribution function (ODF), which is obtained with the help of algorithm in [12]. To do this, small fabric samples of $20 \mathrm{~g} / \mathrm{m} 2$ nonwoven were prepared and their images were taken with scanning electron microscopy (SEM) and X-ray micro computed tomography (CT). The best image, with the clearest view of fibres, was scanned with the help of the algorithm based on image-analysis technique and computed the oriented distribution function of fibres (Fig. 9). Here, 0o corresponds to CD and 90o to MD. Since a bond point in the fabric is not only attached to its adjacent bond points in machine direction rather multiple bond points at an angle to machine direction (see Fig. 1), therefore, only a part of the ODF obtained from the experiments is implemented into the finite element model. The portion of experimental ODF implemented into finite-element model is dependent on the distance between two bond-points as a fibre can achieve maximum angular deviation from the line connecting centres of them when it connects corner node of one bond point and the corner node of the opposite edge of another bond point as shown in Fig. 8. The portion of the ODF which is implemented into the model is shown between dotted lines in Fig. 9.

The approach of direct modelling of fibres in the FE model naturally introduced voids and gaps into it, reflecting the real structure of low-density fibrous networks. The number of fibres modelled between the bond points was exactly the same as in the actual part of the fabric with dimensions equal to those of the FE model. This number can be calculated with the following relation:

$$
\mathrm{N}_{\text {Fibre }}=\frac{\mathrm{m}_{\text {Fibre }}}{\rho \mathrm{AL} \mathrm{L}_{\text {Single_fibre }}},
$$

where $\rho$ is the fibre material density, $A$ is the fibre's cross-sectional area, $m_{\text {Fibre }}$ is the mass of fibres within the modelled part of fabric and $\mathrm{L}_{\text {Single_fibre }}$ is the length of the individual fibre. $\mathrm{m}_{\text {Fibre }}$ was calculated by multiplying the fabric density with the surface area of the modelled fabric sample. $\rho$ and L Single_fibre $_{\text {were }} 20 \mathrm{~g} / \mathrm{m} 2$ and $38.1 \mathrm{~mm}$ in this study, which are equal to the fabric's parameters used in experimentation. The finite-element model was developed with the commercial software package,

MSC.Marc ${ }^{\circ}$, using shell elements for bond points and truss elements for fibres. Numerical simulations of the onset and propagation of damage were carried out by using the critical stress failure criterion. The elementary formulation of this criterion is given as:

$$
\operatorname{If}\left(\frac{\sigma_{1}}{X_{t}, X_{c}}\right),\left(\frac{\sigma_{2}}{Y_{t}, Y_{c}}\right),\left(\frac{\sigma_{3}}{Z_{t}, Z_{c}}\right),\left(\frac{\sigma_{12}}{S_{11}}\right),\left(\frac{\sigma_{23}}{S_{23}}\right),\left(\frac{\sigma_{31}}{S_{31}}\right)=1, \quad d_{\max }=1
$$

Here $\sigma_{1}, \sigma_{2}, \sigma_{3}, \sigma_{12}, \sigma_{23}, \sigma_{31}$ are components of the stress tensor at any integration point of an element. $X_{t}, Y_{t}, Z_{t}, X_{c}, Y_{c}, Z_{c}$ and $S_{13}, S_{23}, S_{31}$ represent longitudinal tensile strength, compressive strength and longitudinal shear strength in 3 directions and 3 planes, respectively. $\mathrm{d}_{\max }$ is the damage variable associated with either of the failure mode of an element depending upon the stresses applied on it 
e.g. failure mode under tension, compressive or shear stress. Since it was observed that fibres re-orient themselves in the loading direction during the tensile test of nonwovens and take only tensile load; therefore, equation 4 can be modified as:

$$
\operatorname{If}\left(\frac{\sigma_{1}}{X_{t}}\right),\left(\frac{\sigma_{2}}{Y_{t}}\right),\left(\frac{\sigma_{3}}{Z_{t}}\right)=1, \quad d_{\text {Tensile }}=1
$$

Here, damage variable is associated with only the tensile failure mode and is represented by $\mathrm{d}_{\text {Tensile }}$. In the FE model, an element (fibre in this study) was assumed to fail during deformation when maximum deformation condition i.e. $\mathrm{d}_{\text {Tensile }}=1$ was satisfied at its integration location. The element was removed from the model when this condition was satisfied to avoid the convergence problem. Besides, a removed element did not offer any resistance to the subsequent deformation.

The simulations were carried out within the framework of quasi-static loading conditions with large displacements and rotations. To simulate the tensile test, a set of boundary conditions was applied to the FE model. The nodes on the bottom side of a bottom bond point were fully constrained whereas a uniform axial displacement condition corresponding to the strain rate of $0.51 / \mathrm{s}$ was applied to the nodes on the top side of another bond point as shown in Fig. 10. The elastic-plastic mechanical properties of material necessary for modelling (flow curve, modulus of elasticity and Poisson's ratio) were determined by the tensile tests of processed single-fibre at strain rate of $0.51 / \mathrm{s}$. The damage parameter corresponding the above criteria used in FE modelling is $\mathrm{Y}_{\mathrm{t}}=240 \mathrm{MPa}$.

\section{Numerical results and discussion}

The computational models with the single-fibre stress-based failure criteria for simulation of damage development until fracture in low-density thermally bonded nonwovens were developed. The deformation and damage behaviour observed during experiments were compared with the models' prediction. The responses of the models with random and straight fibres are shown in Figs. 11 and 12, respectively.

The model consisting of parallel fibres between the bond points was not only lacking in representing the randomness in microstructure similar to that of the actual material but also failed to account for reorientation of fibres during initial stages of deformation, which is the key feature of deformation and fracture of nonwoven fabrics. Moreover, this model is incapable to represent the gradual increase in failure of fibres with fabric extension observed during the experiments as almost all the fibres failed nearly simultaneously at $75 \%$ fabric extension. Due to the edge effects involved, a few fibres left at that level of fabric extension (Fig. 11d) failed with further fabric extension. The visualization of fibre failure along with von Mises stresses in parallel fibres model at different levels of strain is given in Fig. 11. However, the model consisting of randomly oriented fibres between the bond points represented the randomness in microstructure similar to that of studied material as well as the deformation and damage behaviour observed during the tensile tests. At the initial stages of stretching, randomly oriented fibres 
(shown in Fig. 12a) are extensively reoriented to become aligned along the loading direction (see Fig. 12b). In this way, they started participating more in load bearing and underwent elastic-plastic deformation due to the material properties assigned. With continuing extension of the fabric, strain and corresponding stresses increased in fibres. The fibres with the applied stresses reaching their threshold failed triggering damage in nonwoven. These failed fibres caused the development of local fracture zones made up by the remaining fibres aligned along loading direction as shown in Fig. 12d. The complete failure of fabric did not follow immediately after the onset of macroscopic damage but occurred as a progressive failure of fibres. This sequence of damage is similar to the one observed during fabric's tensile deformation and failure experiments. In simulations, the failed fibres were removed to avoid the convergence problem.

The damage evolution in nonwovens can be characterised by a ratio $\mathrm{N}_{\mathrm{f}} / \mathrm{N}$, where $\mathrm{N}_{\mathrm{f}}$ is the accumulated number of fibres failed at any particular level of fabric extension and $\mathrm{N}$ is the total number of fibres. This damage parameter $\mathrm{N}_{\mathrm{f}} / \mathrm{N}$ as a function of fabric extension for both — parallel and random fibres - models is given in Fig. 13. This shows that in the parallel-fibres model, ultimate failure of fabric occurred immediately at $75 \%$ extension, whereas damage grew comparatively slow with the fabric extension after the failure of the first fibre in the random-fibres model. This progressive damage caused by continuous failure of fibres in the model with randomly oriented fibres is the key feature of deformation and failure of nonwoven fabrics, which was not represented by parallel fibres model. Hence, this study also shows the importance of introducing randomness into numerical models for nonwovens.

These simulations were carried out by assuming that all the fibres had the same material properties. As there was a significant scatter in material properties obtained from the single-fibre experiments, another series of simulations including randomness of fibre material properties was also implemented with the FE model. The model with randomly oriented fibres was used for this purpose as it is closer to realistic microstructure of the fabric. The randomness of material properties implemented in the model was not only in terms of damage parameters but also the entire flow curve; various stress-strain curves were randomly assigned to truss elements in the FE model. The scatter in material properties obtained for processed fibres at strain rate of $0.51 / \mathrm{s}$ was used for this purpose since the same strain rate was applied as boundary condition in the model. The corresponding results for evolution of the damage parameter $\mathrm{N}_{\mathrm{f}} / \mathrm{N}$ with fabric extension are plotted in Fig. 14. When these results are compared with those for the model with randomly oriented fibres each with the same (average) material properties, a more gradual growth of damage, started at a lower strain level approximately $34 \%$ was observed; in the model with similar fibres it was $74 \%$. Moreover, this fibre-failure process remained continuous with increase stretching of the fabric until the final fibre failed at a strain level of $112 \%$ as shown in Fig. 14. This gradual growth of damage in the random-fibre material model is closer to the deformation and failure behaviour of nonwovens observed experimentally, in which fibre failure process started at $35 \%$ to $40 \%$ and gradually grew until $112 \%$ to $120 \%$ of fabric extension. Thus, a model with randomness both in fibre orientation and their material properties is more suitable to simulate the realistic deformation and failure process of nonwovens. As scatter in material properties can be randomly assigned to various fibres in FE 
model in multiple ways, simulations of numerous statistical realizations can be performed by assigning different combinations of fibre orientation and material properties, eliminating the serrated behaviour of the averaged curve of damage parameter as a function of fabric extension.

In order to study the importance of damage criteria based on mechanical properties of processed fibres extracted from nonwoven, simulations of another tensile test was carried by implementing the damage criteria based on properties of unprocessed fibres. The material properties obtained from the single-unprocessed-fibre tensile tests at strain rate of $0.51 / \mathrm{s}$ were used for this purpose. The results in terms of damage parameter as a function of fabric extension are shown in Fig. 15, which demonstrates that the fibre-failure process started at fabric extension of approximately $200 \%$ followed by ultimate failure of fabric at $379 \%$. Both of these values - damage initiation and ultimate failure - are significantly higher than experimental results, which are closer to those of the model with material properties of processed fibres. Thus, it is important to use material properties, especially damage criteria, for the fibres extracted from the fabric rather than those of unprocessed fibres properties for realistic simulations of deformation and failure of nonwovens.

\section{Conclusions}

A novel method is used to develop damage criteria based on single-fibre failure in a thermally bonded nonwoven, since experimental observation of stretching of low-density thermally bonded nonwovens demonstrate a character of fibres failure leading to ultimate fabric failure. Experimental mechanical characterization of single fibre, extracted from nonwoven with a bond point attached at its each end, revealed the scatter in breaking stress and strain at failure of individual fibres. Tensile tests of unprocessed fibres, which were used to manufacture this fabric, were also performed to quantify the loss in strength of individual fibre due to the bonding process. The stress-strain behaviour of single fibres, extracted from the nonwoven material, was used as basis for properties required for the numerical model. The critical value of stress, at which a single fibre fails, was used as damage criterion for the model. Damage criteria developed by this technique can be implemented directly into a FE model of nonwoven based on direct introduction of fibres to reflect its realistic microstructure.

A numerical (FE) model was developed to study the mesoscopic deformation as well as onset and propagation of damage until failure of the low-density thermally bonded nonwoven. Two types of fibre orientations between the neighbouring bond points were used. Capabilities of the models were assessed in comparison to tensile loading experiments. This approach enabled a straight-forward microstructure-based numerical model maintaining the relation between microstructure of a nonwoven and its deformation and, especially, damage behaviour. The model with both random orientation of fibres and random material properties reproduced not only the realistic microstructure of the fabric but also main mechanisms of mesoscopic uniaxial deformation and damage of thermally bonded nonwovens. Thus, this model can be extended to analyse the macro level to behaviour of thermally bonded nonwovens until their fracture. The material properties, implemented in the model, should be based on those of processed fibres extracted from the fabric rather than unprocessed ones since the model of the latter case 
resulted in a significantly higher level of critical fabric extension. Ultimately, the technique used for developing and implementing realistic damage criteria into a computational model can help to produce more reliable and durable nonwovens.

\section{Acknowledgement}

We greatly acknowledge support by the Nonwovens Cooperative Research Centre of North Carolina State University, Raleigh, USA. FiberVisions ${ }^{\circledR}$, USA generously provided the material for this study. We also acknowledge the use of Photrom (Fastcam SA3), borrowed from the EPSRC UK Engineering Instrument Pool.

\section{References}

[1] Russell S J (2007) Handbook of Nonwovens: Woodhead Publishing Limited.

[2] Albrecht W, Fuchs H, Kittelmann W (2003) Nonwoven fabrics: raw materials, manufacture, applications, characteristics, testing processes: Wiley-VCH Weinheim.

[3] Chidambaram A, Davis H, Batra S (2000) Strength loss in thermally bonded polypropylene fibres. Inter Nonwovens J 9:27-35.

[4] Wang X, Michielsen S (2001) Morphology gradients in thermally point-bonded polypropylene nonwovens. Textile Res J 71:475-480.

[5] Wang X, Stephen M (2002) Morphology gradients in thermally point-bonded poly (ethylene terephthalate) nonwovens. Textile Res J 702:394-398.

[6] Michielsen S, Pourdeyhimi B, Desai P (2006) Review of thermally point-bonded nonwovens: materials, processes and properties. J Appl Polymer Sci 99:2489-2496.

[7] Michielsen S, Wang X (2002) Rapid morphology (property) changes at the bond periphery in thermal point-bonded nonwovens. Int Nonwovens J 2002 11:35-38.

[8] Dharmadhikary R K, Davis H, Gilmore T F, Batra S K (1999) Influence of fibre structure on properties of thermally point bonded polypropylene nonwovens. Textile Res J 69:725-734.

[9] Hedge R R, Bhat G S, Campbell R A (2008) Thermal bonding of polymer films and fibres. J Appl Polymer Sci 2008 110:3047-3058.

[10] Bhat G S, Jangala P K, Spruiell J E (2004) Thermal bonding of polypropylene nonwovens: effect of bonding variables on the structure and properties of the fabric. J Appl Polymer Sci 2004 92:3593-3600. 
[11] Demirci E, Hou X, Acar M, Pourdeyhimi B, Silberschmidt V V (2012) Numerical modelling of thermally bonded nonwovens: continuous and discontinuous approaches. Solid State Phen 188:164-169.

[12] Demirci E, Acar M, Pourdeyhimi B, Silberschmidt V V (2012) Computation of mechanical anisotropy in thermally bonded component fibre nonwovens. Comput Mater Sci 52:157-163.

[13] Demirci E, Acar M, Pourdeyhimi B, Silberschmidt V V (2011) Dynamic response of thermally bonded bicomponent fibre nonwovens. Appl Mech Mater 70:410-415.

[14] Demirci E, Acar M, Pourdeyhimi B, Silberschmidt V V (2011) Finite element modelling of thermally bonded bicomponent fibre nonwovens: tensile behaviour. Comput Mater Sci 50:1286-1291.

[15] Demirci E, Acar M, Pourdeyhimi B, Silberschmidt V V (2010) ASME Conf Proc; ESDA2010: 117 122.

[16] Sabuncuoglu B, Acar M, Silberschmidt V V (2012) A parametric finite element analysis method for low-density thermally bonded nonwovens. Comput Mater Sci 52:164-170.

[17] Hou X, Acar M, Silberschmidt V V (2011) Finite element simulation of low-density thermally bonded nonwoven materials:effect of orientation distribution function and arrangement of bond points. Comput Mater Sci 50:1292-1298.

[18] Hou X, Acar M, Silberschmidt V V (2011) Non-uniformity of deformation in low-density thermally bonded nonwoven material: effect of microstructure. J Mater Sci 46:307-315.

[19] Hou X, Acar M, Silberschmidt V V (2009) 2D dinifte element analysis of thermally bonded nonwoven materials: continuous and discontinuous models. Comput Mater Sci 46:700-707.

[20] Farukh F, Demirci E, Sabuncuoglu B, Acar M, Pourdeyhimi B, Silberschmidt V V (in press) Numerical modelling of damage initiation in low-density thermally bonded nonwovens. Comput Mater Sci doi: 10.1016/j.commatsci.2012.05.038.

[21] Rawal A, Priyadarshi A, Lomov S V, Verpoest I J, Vankerrebrouck J (2010) Tensile behaviour of thermally bonded nonwoven structures: model description. J Mater Sci 45:2274-2284.

[22] Rawal A, Priyadarshi A, Kumar N (2010) Tensile behaviour of nonwoven structures: comparison with experimental results. J Mater Sci 45:6643-6652.

[23] Schulgasser, K (1981) On the in-plane elastic constants of paper. Fibre Sci Technol 15:257-270.

[24] Ostoja-Starzewski M, Stahl D C (2000) Random fibre networks and special elastic orthotropy of paper. J Elasticity 60:131-1349.

[25] Isaksson P, Hagglund R (2007) Analysis of the strain field in the vicinity of a crack-tip an in-plane isotropic paper material. Int J Solids Struct 44:659-671. 
[26] Isaksson P, Hagglund R, Gradin P (2004) Continuum damage mechanics applied to paper. Int J Solids Struct 41:4731-4755.

[27] Farukh F, Demirci E, Acar M, Pourdeyhimi B, Silberschmidt V V (2012) J Phys accepted. 


\section{Figure Captions}

Fig. 1 SEM images of $30 \mathrm{~g} / \mathrm{m} 2$ PP fibre nonwoven at different length scales: (a) overall microstructure; (b) bond point and surrounding fibre matrix; (c) polypropylene fibres

Fig. 2 Characteristic force $v s \%$ extension curve of fabric

Fig. 3 Deformation and damage micromechanisms in low-density thermally bonded nonwovens during tensile tests at $0 \%$ strain (a); $25 \%$ strain (b); $50 \%$ strain (c); $80 \%$ strain (d). Loading direction was vertical

Fig. 4 (a) Single fibre attached to bond points at each end (dashed line is used to enhance contrast of image); (b) schematics of final specimen and its fixture

Fig. 5 Setup of single-fibre experiment (Instron Micro Tester 5848 and Photrom Fastcam SA3)

Fig. 6 Scatter in experimental results of processed PP fibres

Fig. 7 Mechanical behaviour of unprocessed (a) and processed (b) PP fibres at various strain rates

Fig. 8 Maximum orientation of fibres in relation to distance between bond points

Fig. 9 Fibres orientation distribution function

Fig. 10 Finite element models: (a) with parallel fibres; (b) with random fibre network between two bond points

Fig. 11 FE results of model with parallel fibres showing development of fracture zone and equivalent von Mises stresses (in MPa) in thermally bonded nonwovens at various levels of global strain: (a) 0\%; (b) $25 \%$; (c) $50 \%$; (d) $75 \%$ (Arrow indicates a fracture zone)

Fig. 12 FE results of model with randomly oriented fibres showing development of fracture zones and equivalent von Mises stresses (in MPa) in thermally bonded nonwovens at various levels of global strain: (a) $0 \%$; (b) $25 \%$; (c) $50 \%$; (d) $75 \%$ (Arrows indicate local fracture zones) 
Fig. 13 Effect of fibre orientation on damage initiation and propagation in FE simulations

Fig. 14 Effect of randomness of fibre material properties on damage initiation and propagation in FE simulations

Fig. 15 Effect of state (processed and unprocessed) of fibres on damage initiation and propagation in FE simulations 
Table 1. Mean values and standard deviation of failure stress and strain of virgin and processed fibres at various strain rates

Strain rate $(1 / \mathrm{s})$

Failure stress

(MPa)

Strain at failure stress

\begin{tabular}{llcc}
\hline 0.01 & Processed fibre & $481 \pm 48$ & $1.29 \pm 0.67$ \\
& Unprocessed fibre & $1299 \pm 95$ & $2.93 \pm 0.78$ \\
0.1 & Processed fibre & $315 \pm 28$ & $1.05 \pm 0.11$ \\
& Unprocessed fibre & $998 \pm 57$ & $1.77 \pm 0.09$ \\
& Processed fibre & $241 \pm 53$ & $0.79 \pm 0.1$ \\
& Unprocessed fibre & $818 \pm 60$ & $1.49 \pm 0.14$ \\
\hline
\end{tabular}




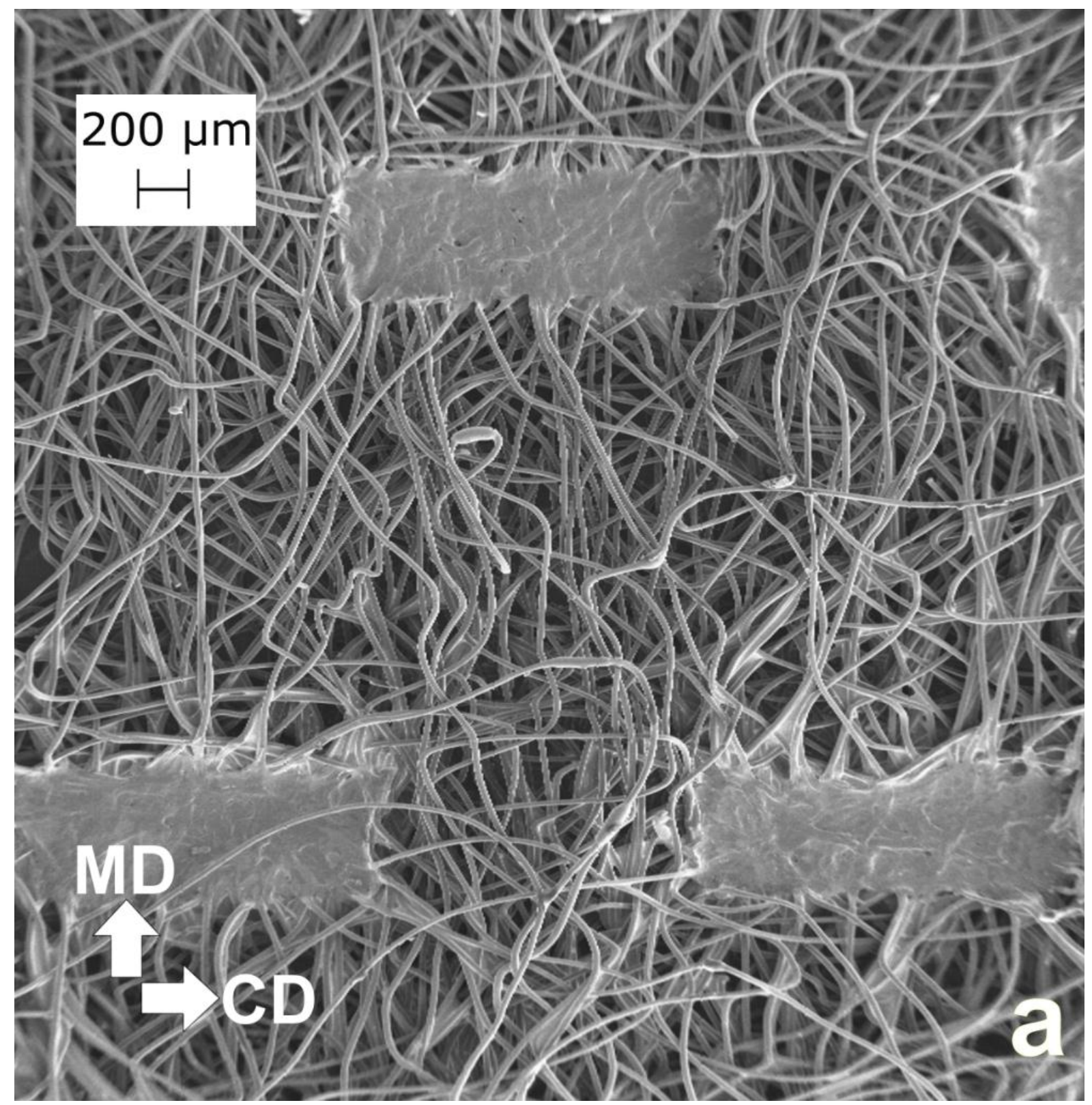

Fig_1_a 


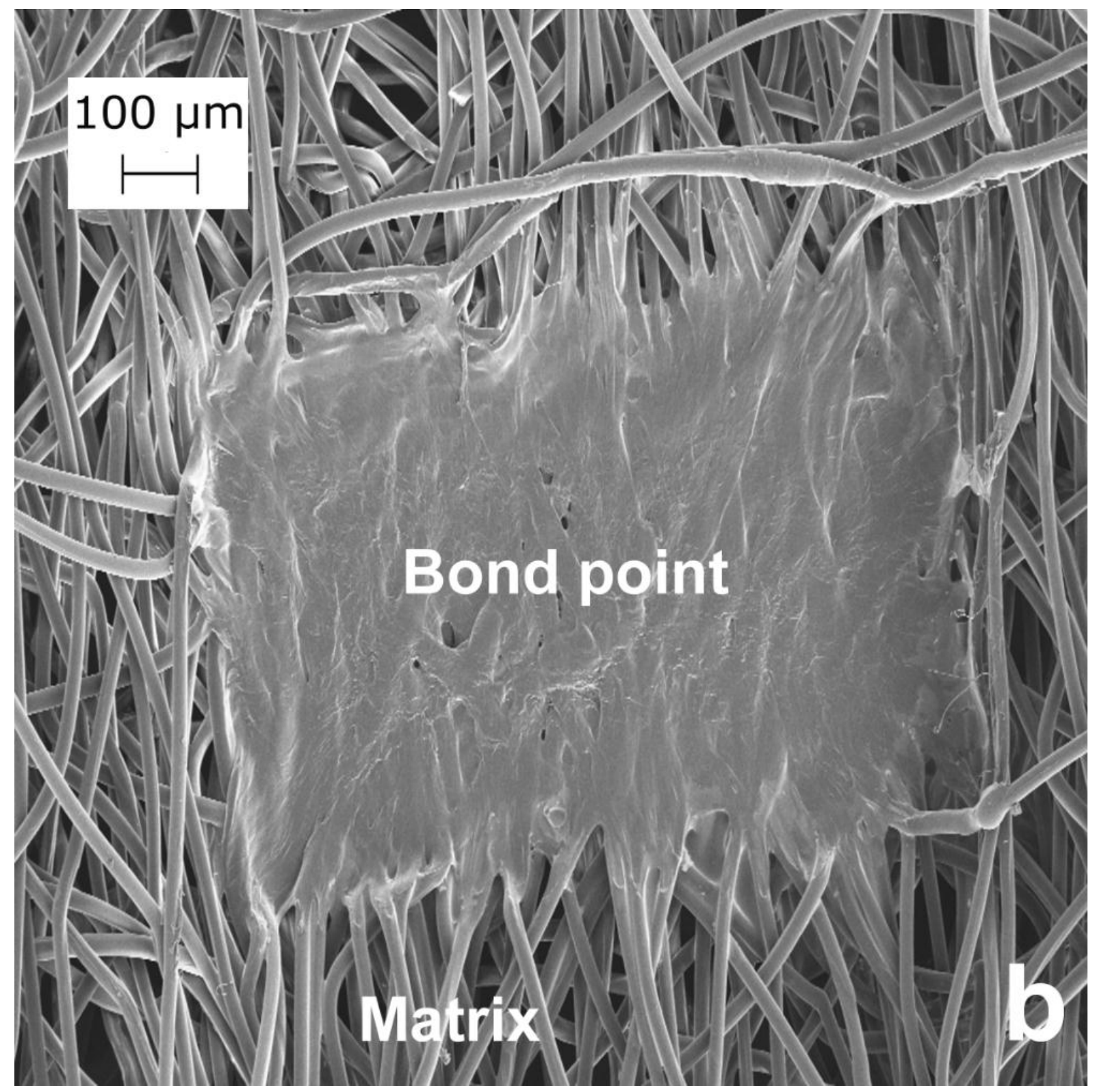

Fig_1_b 


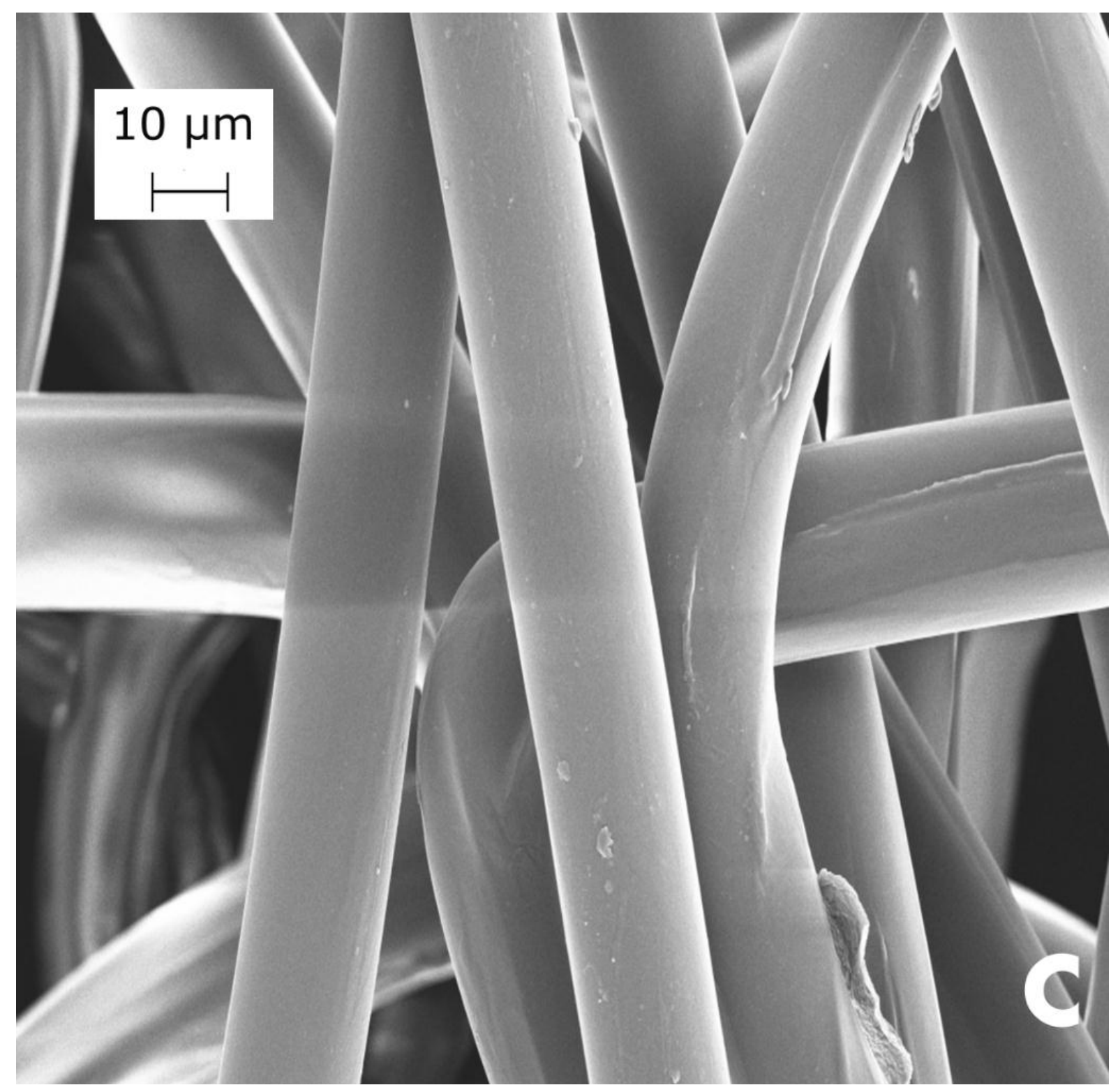

Fig_1_c 


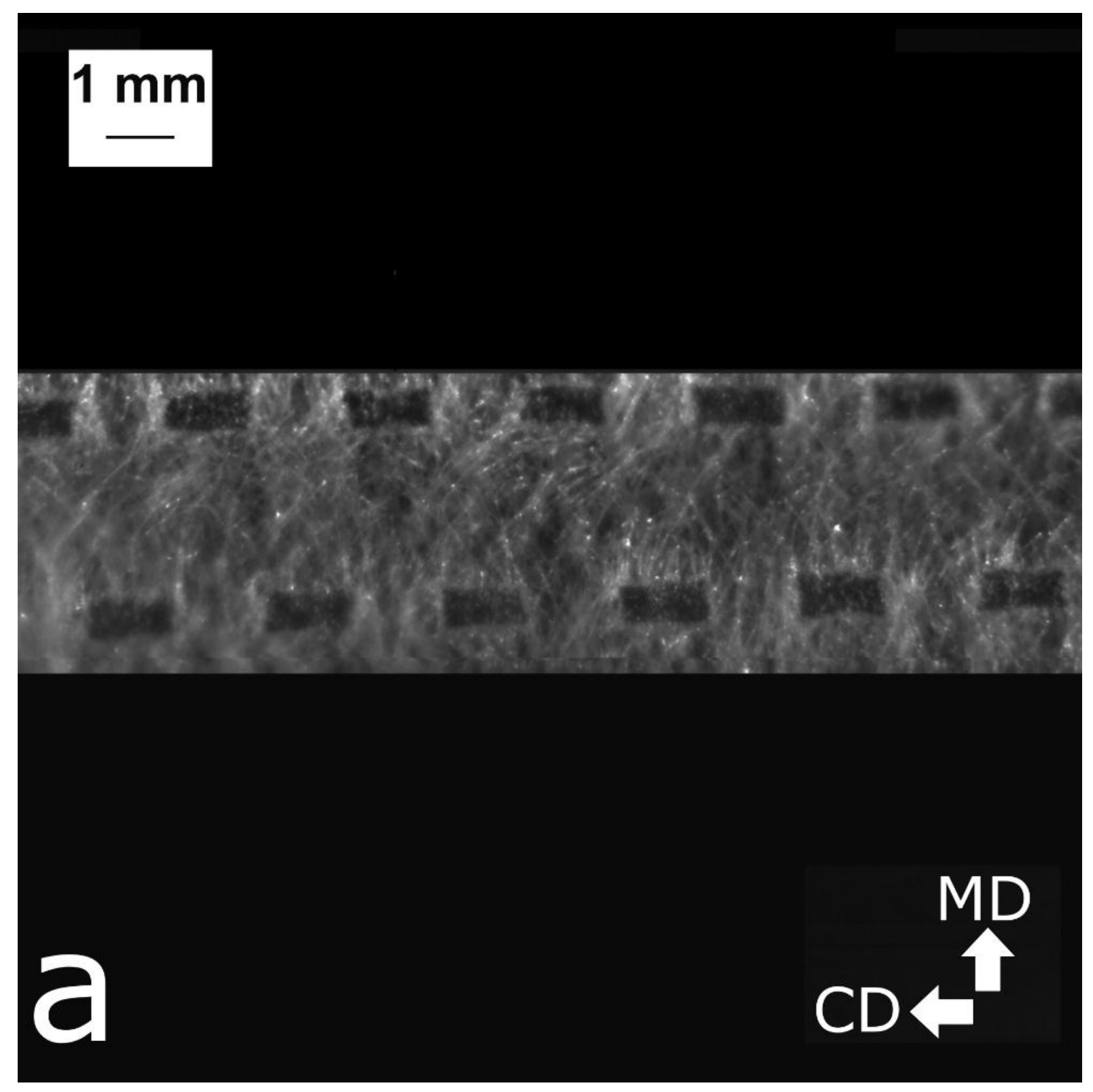

Fig_2_a 


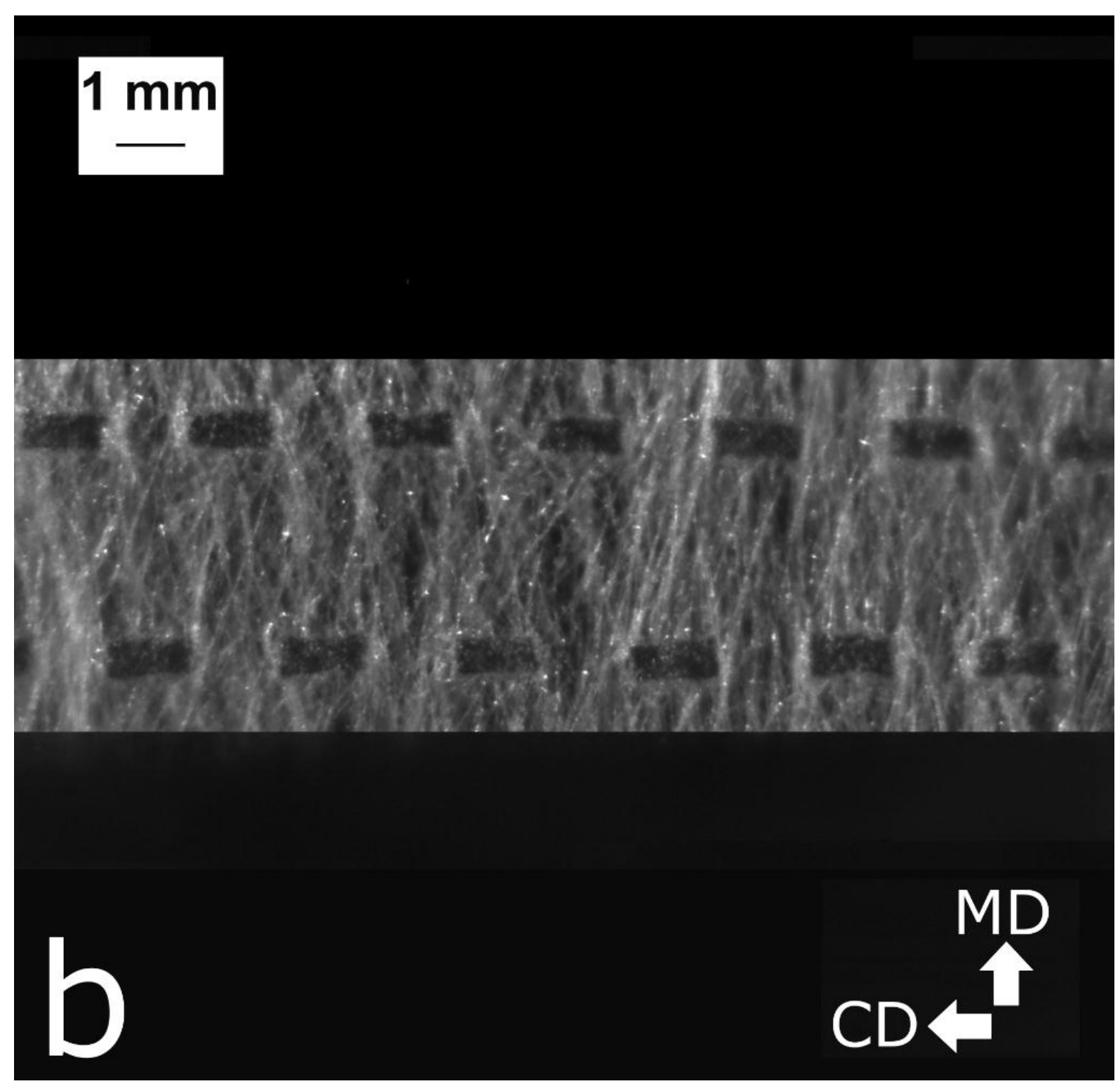

Fig_2_b 


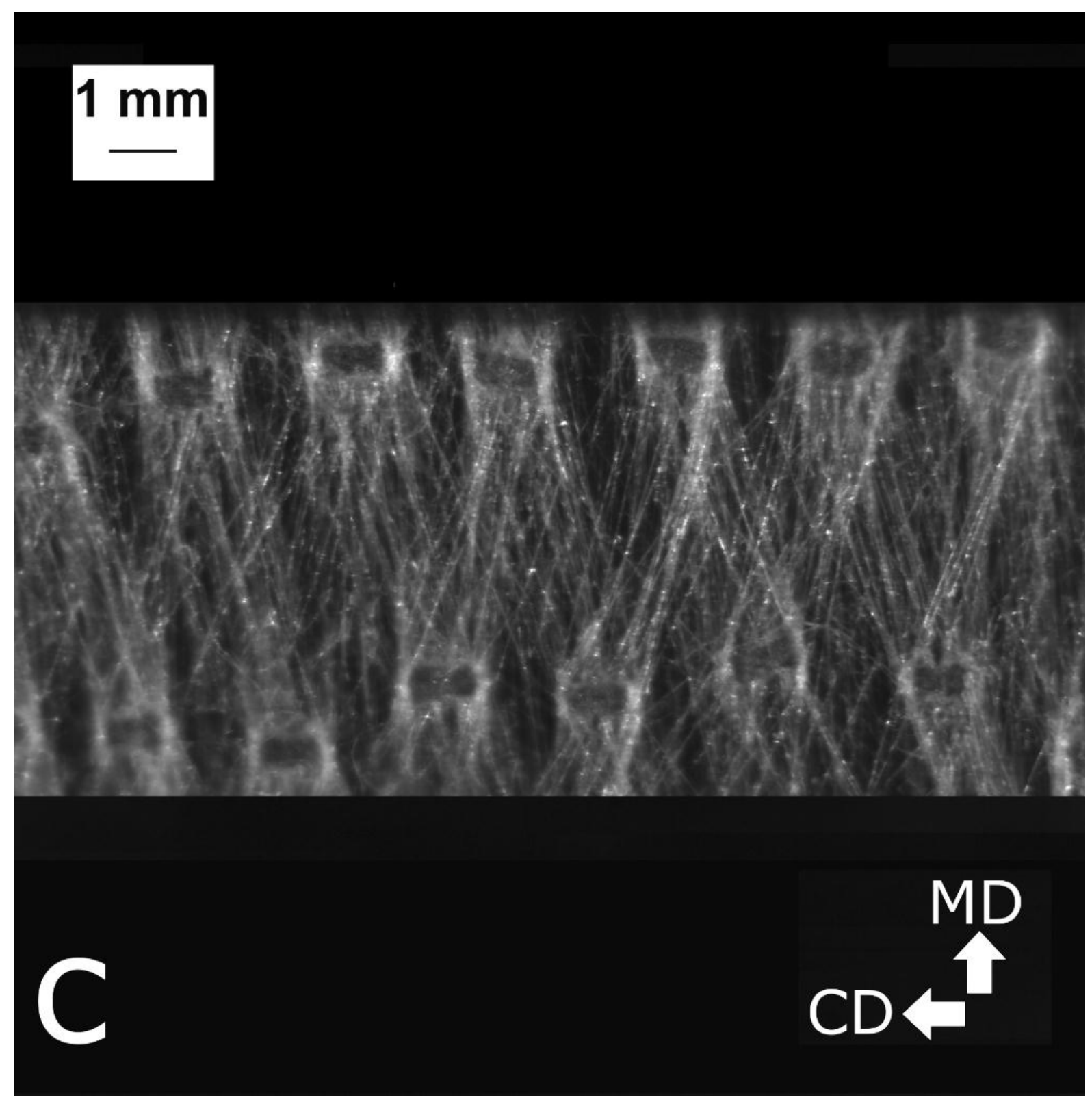

Fig_2_c 


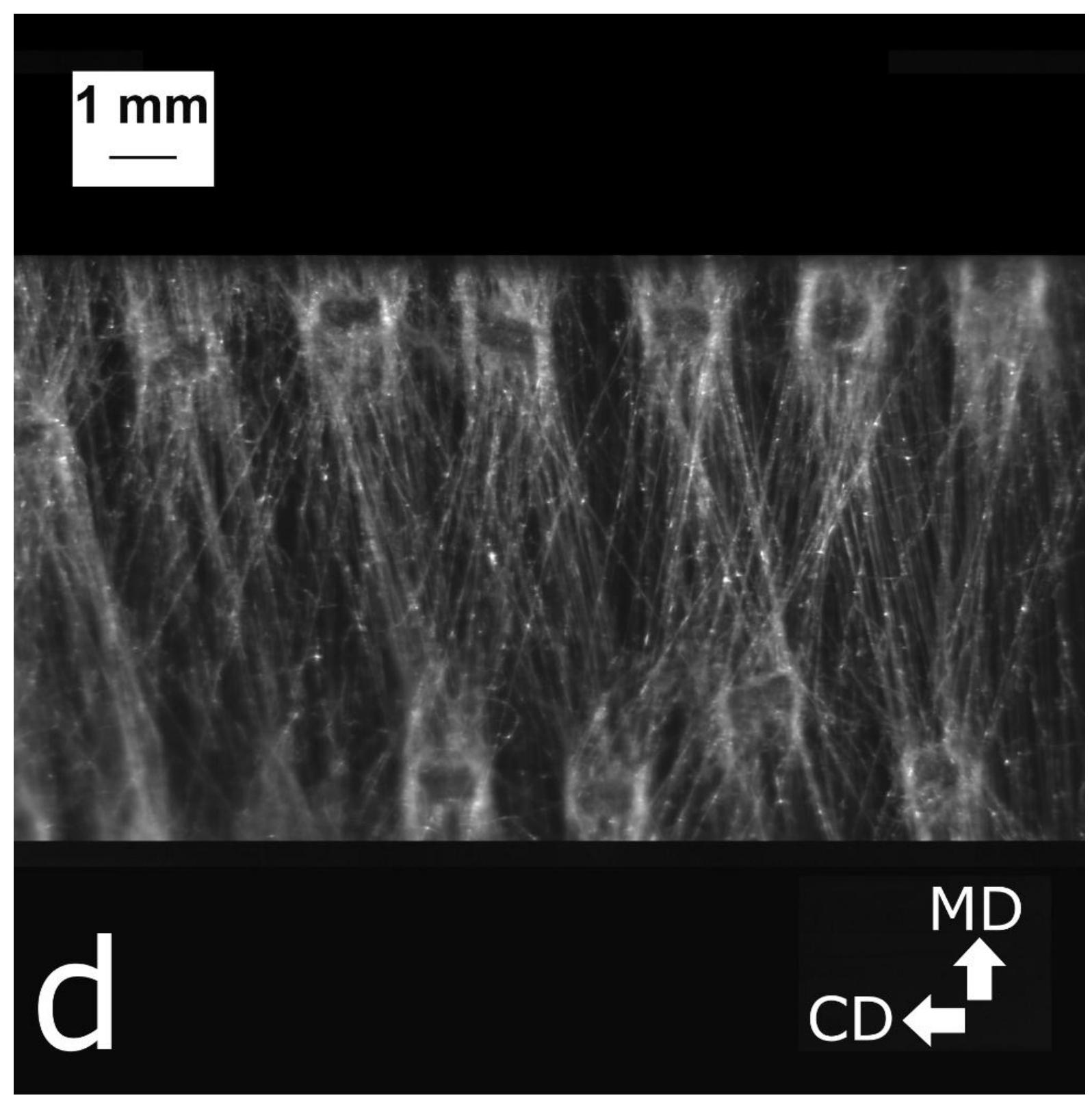

Fig_2_d 


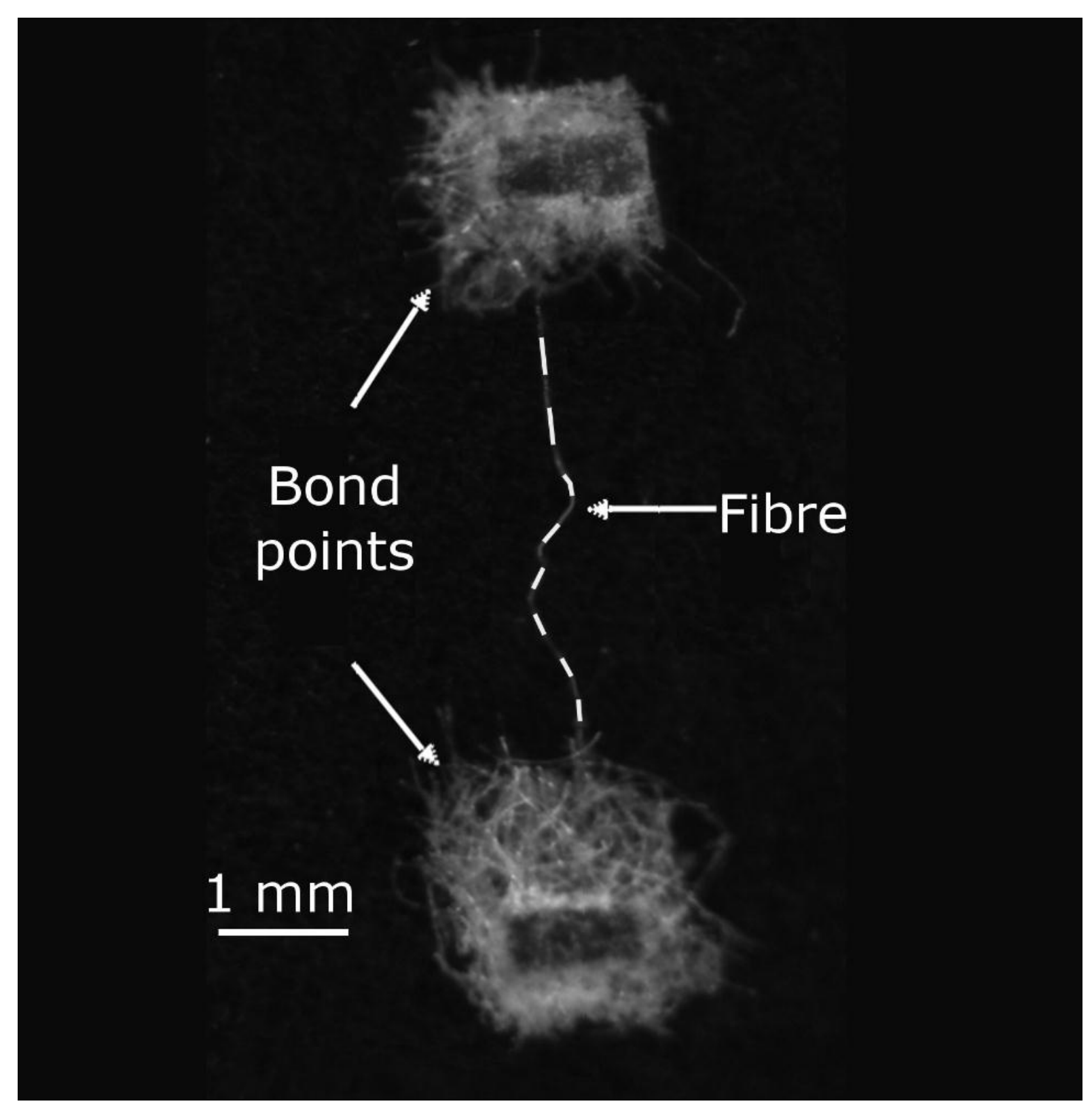

Fig_3_a 


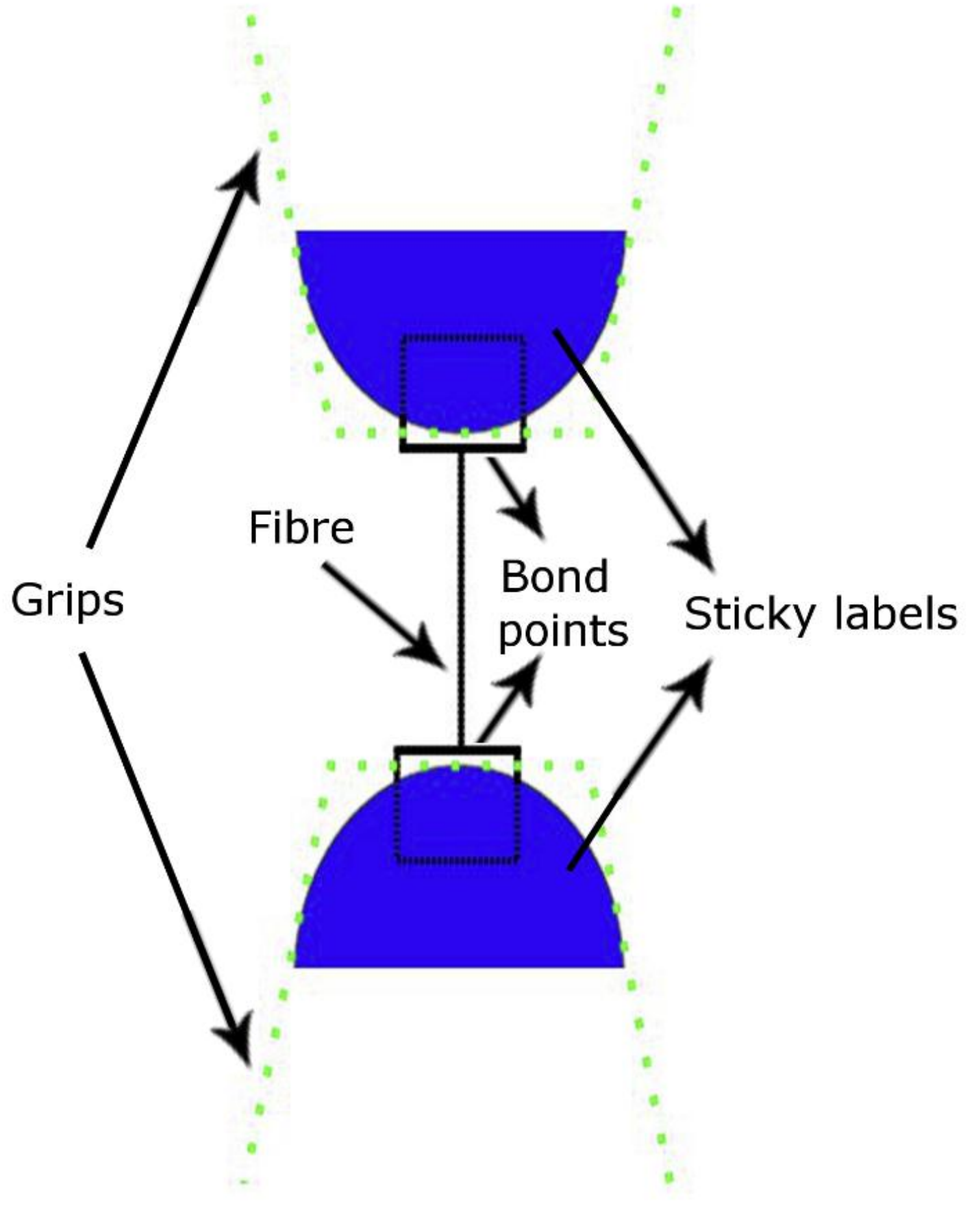

Fig_3_b 


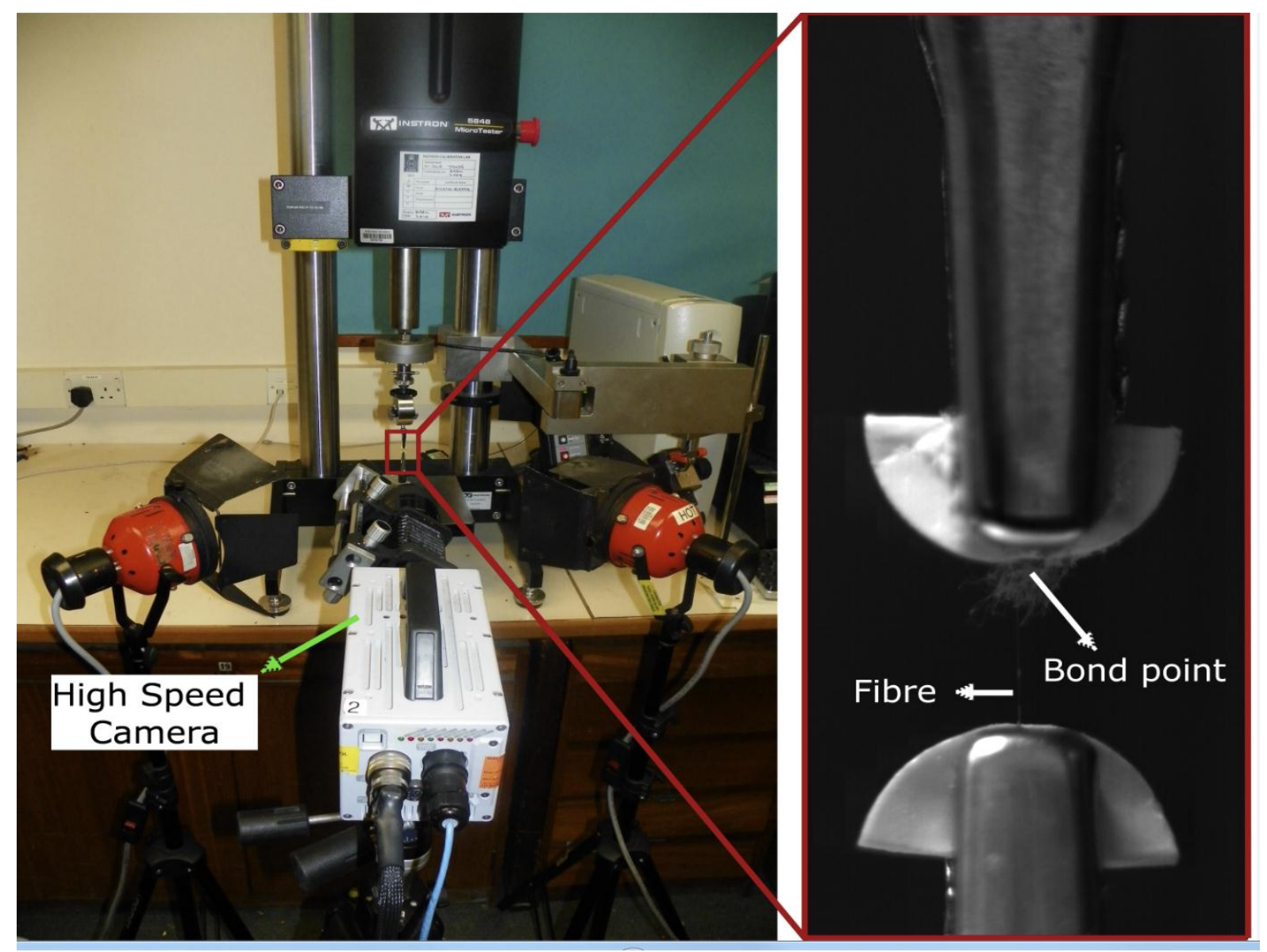

Fig_4 


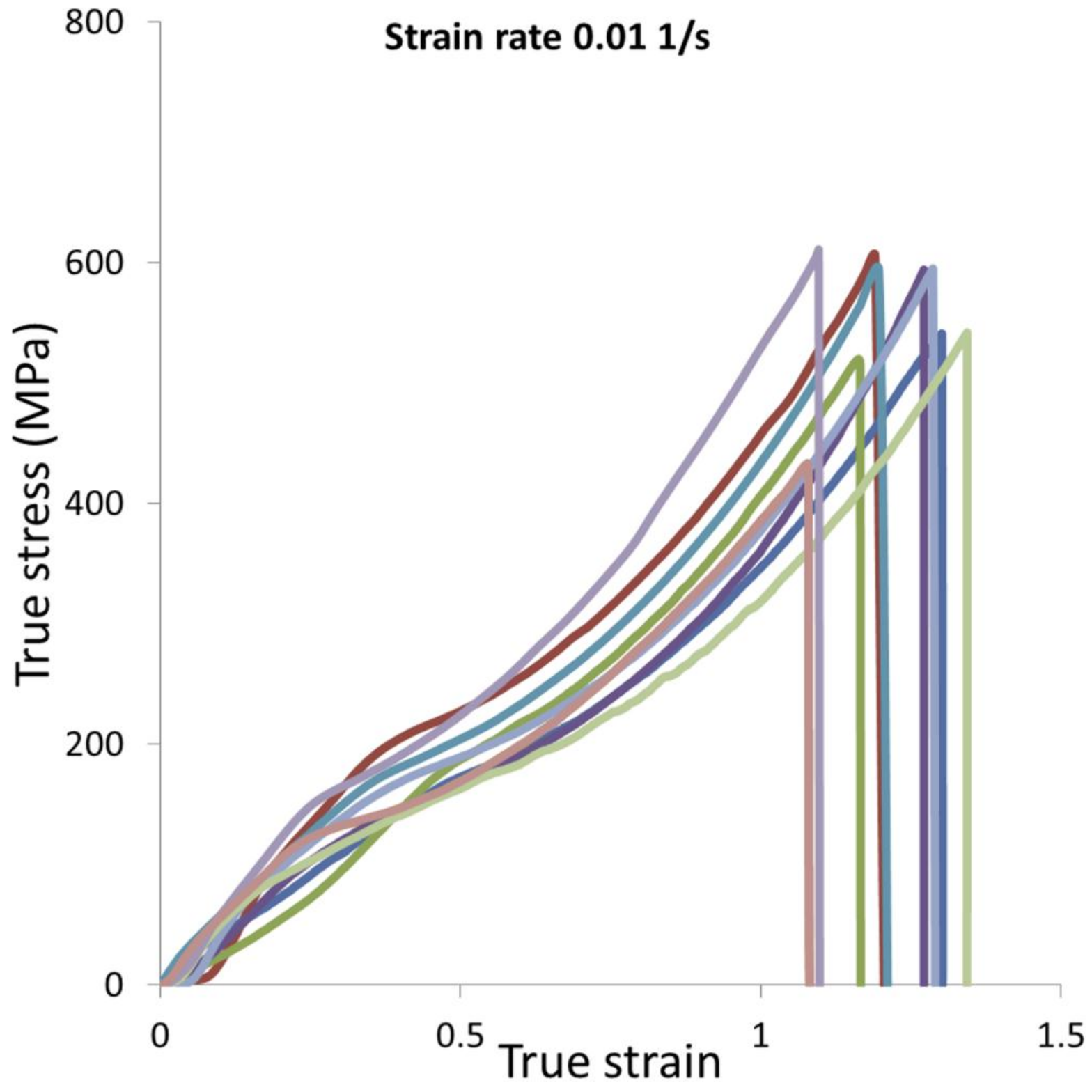

Fig_5 


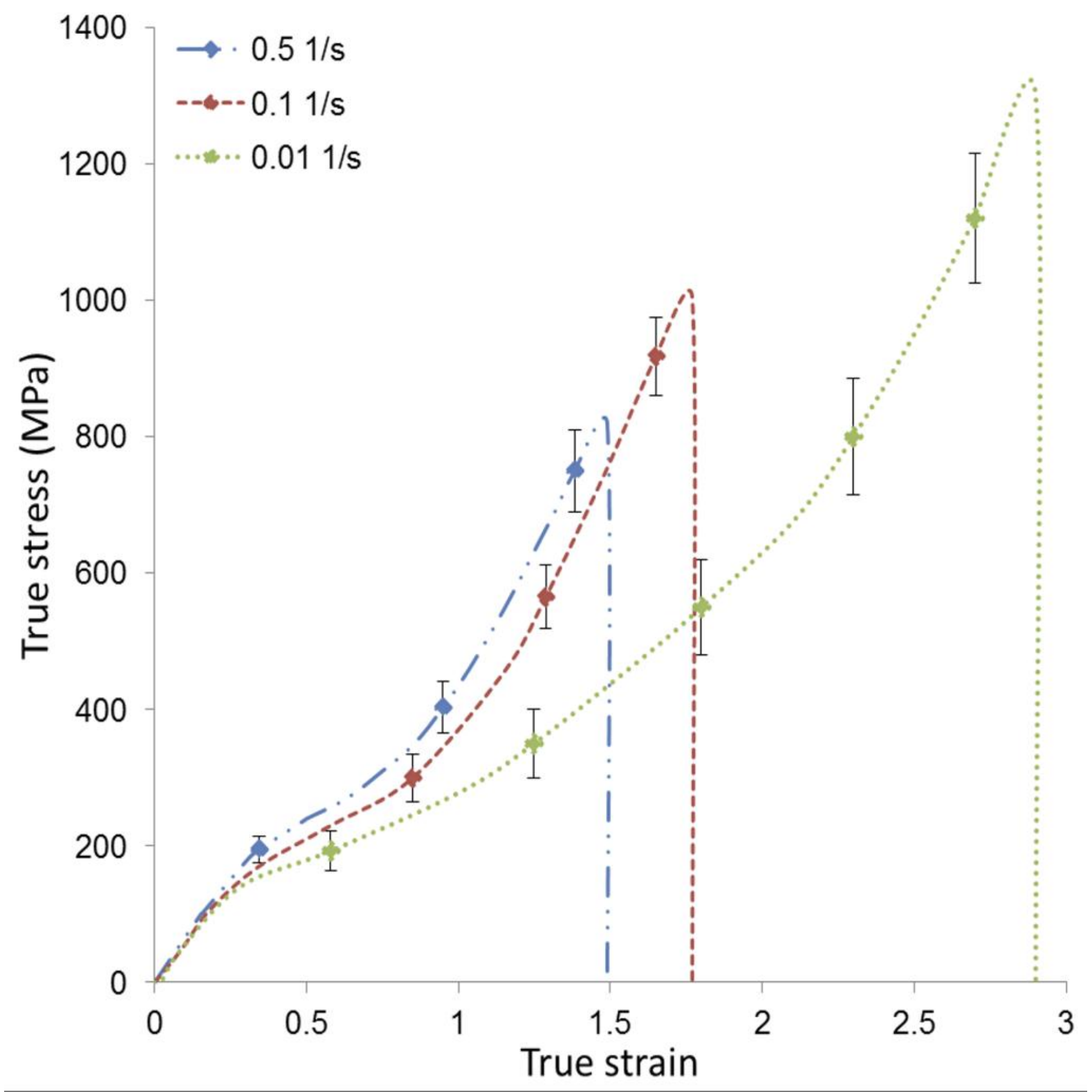

Fig_6_a 


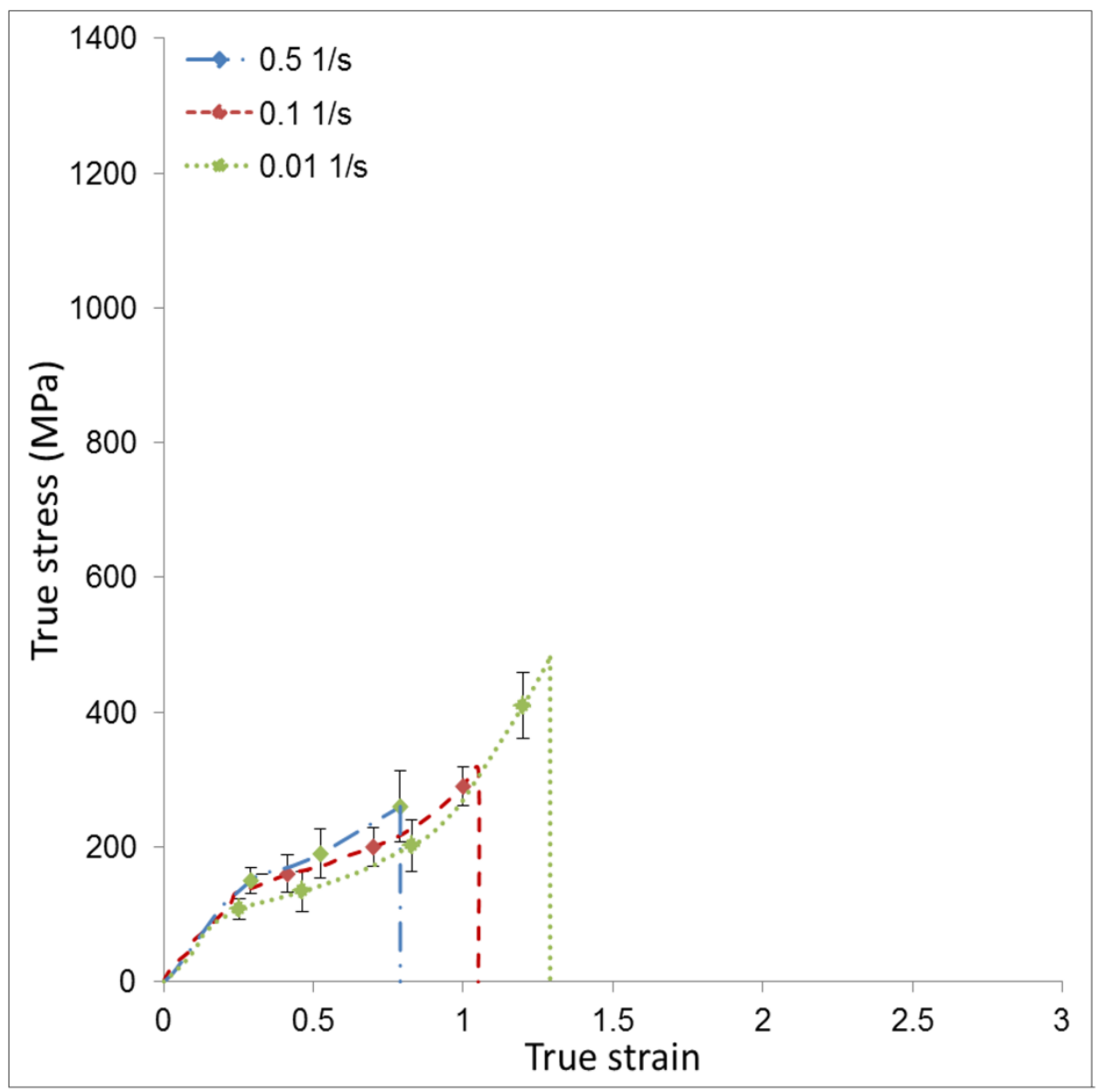

Fig_6_b 


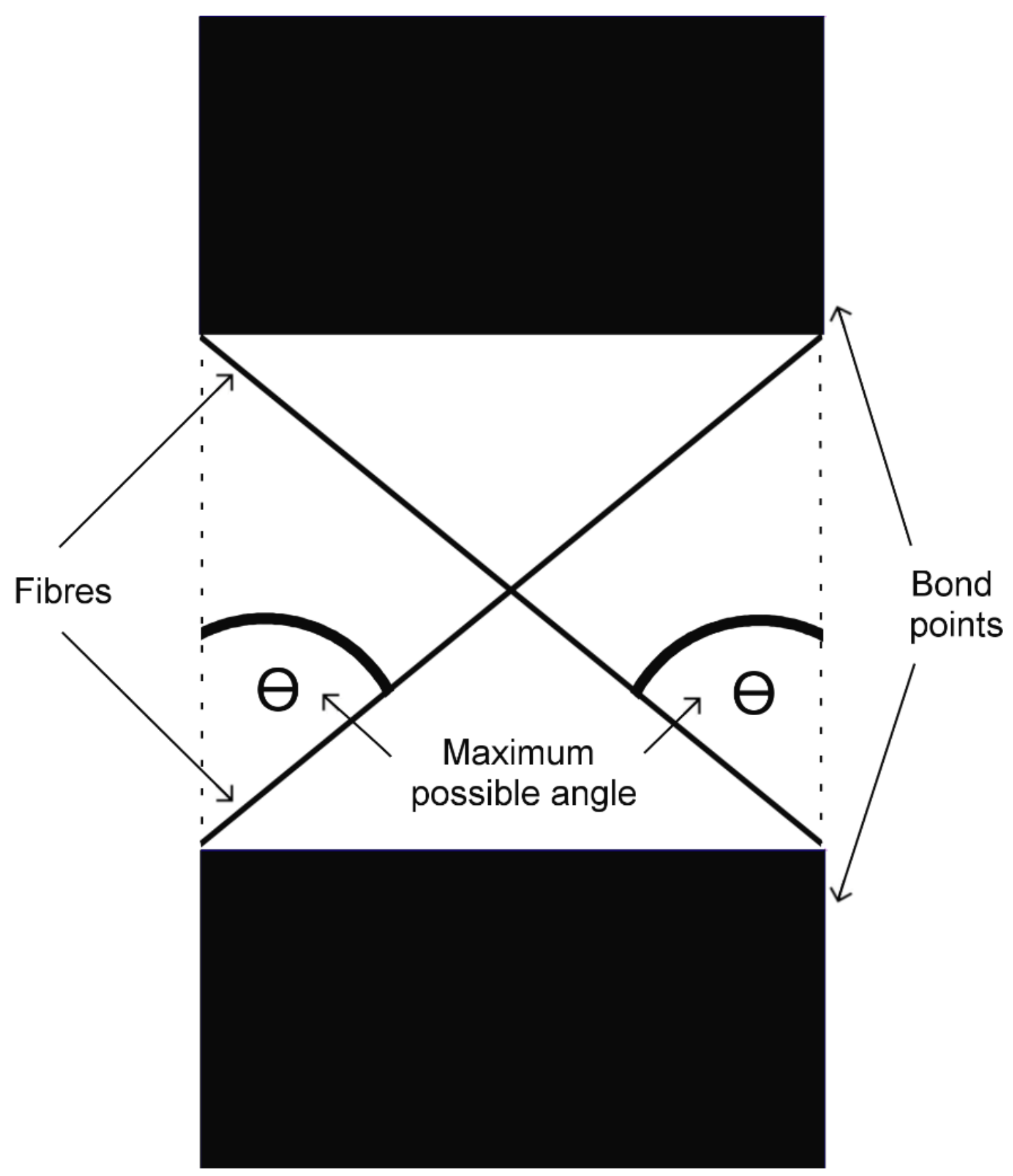

Fig_7 


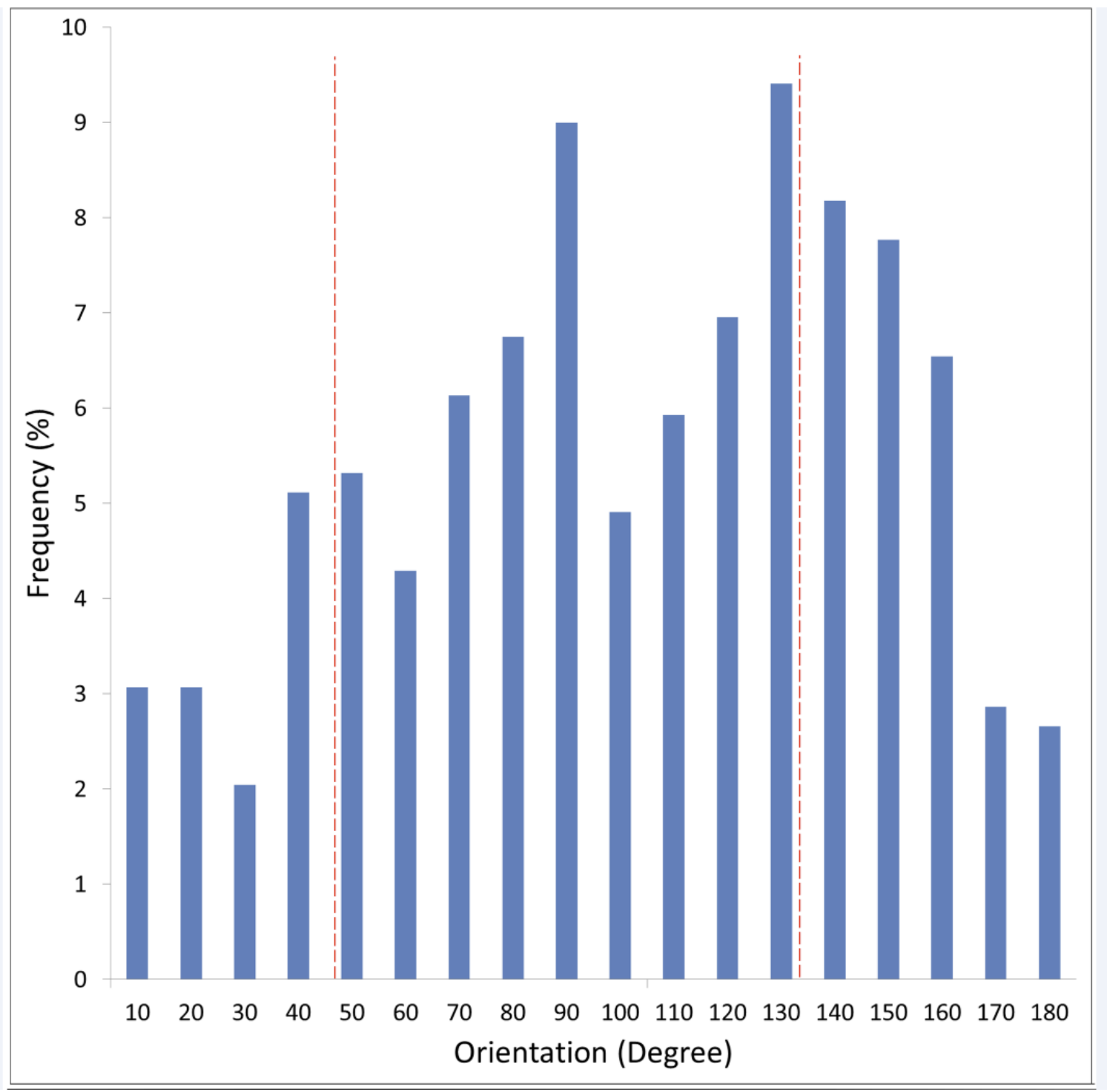

Fig_8 

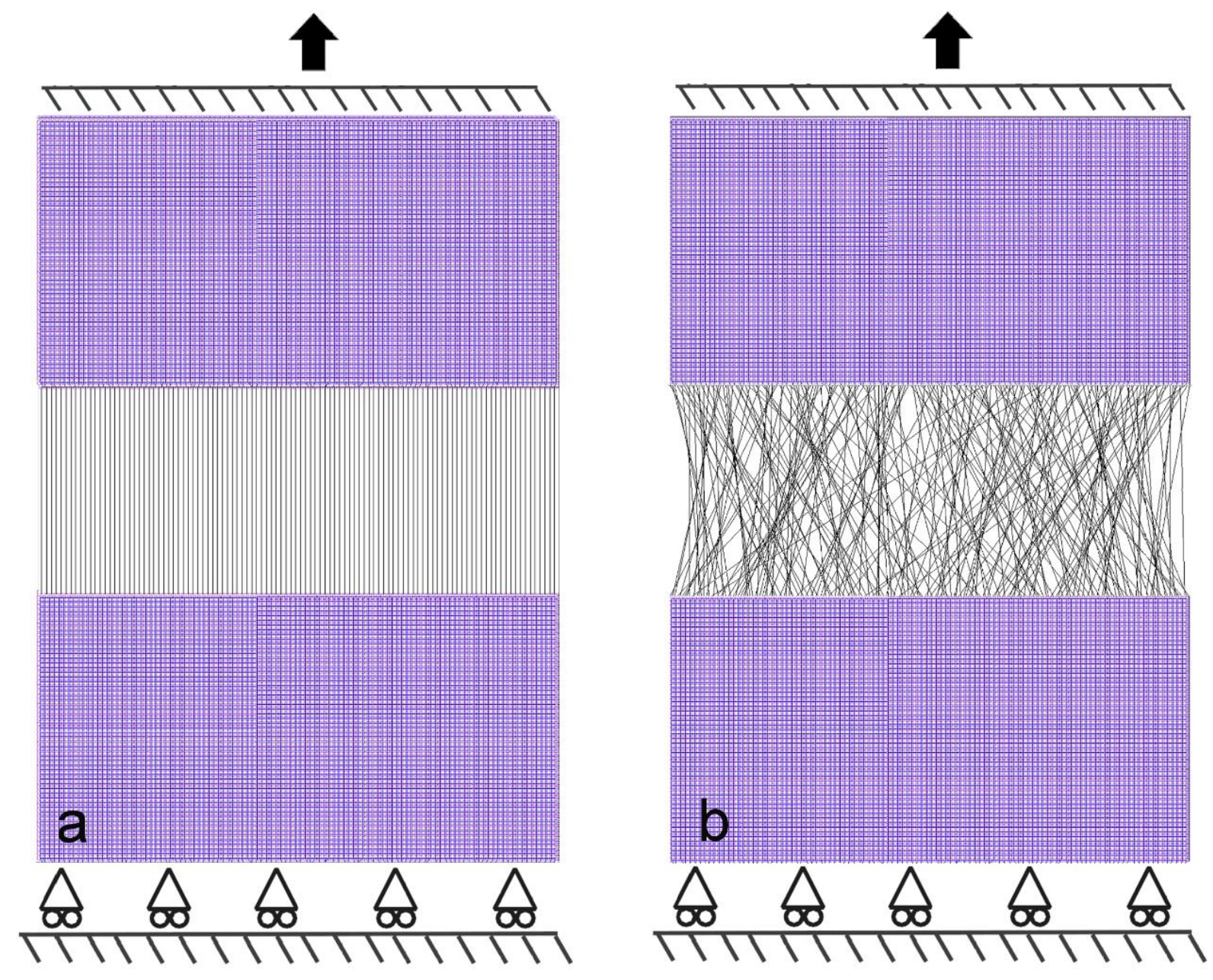

Fig_9 


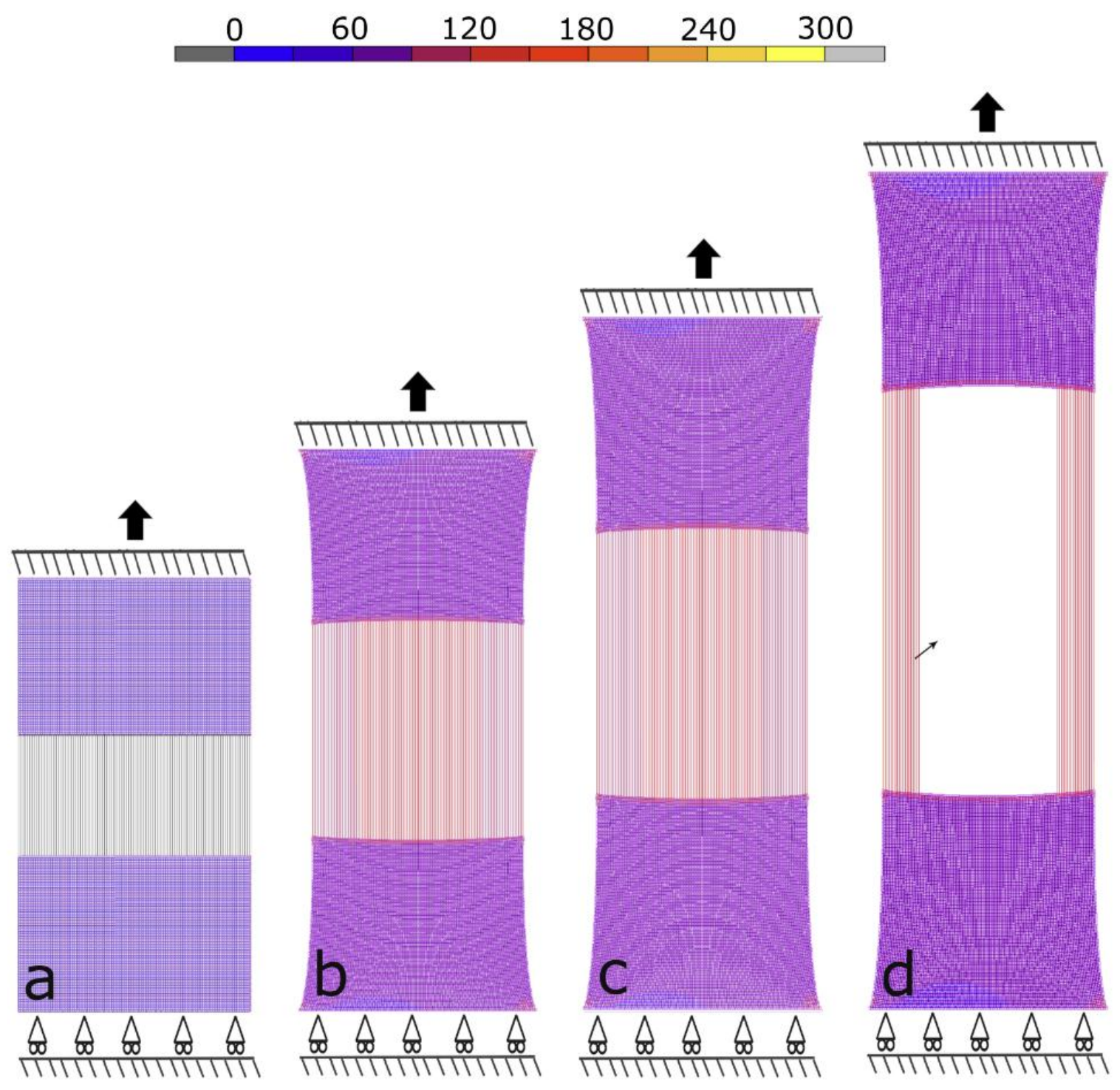

Fig_10 


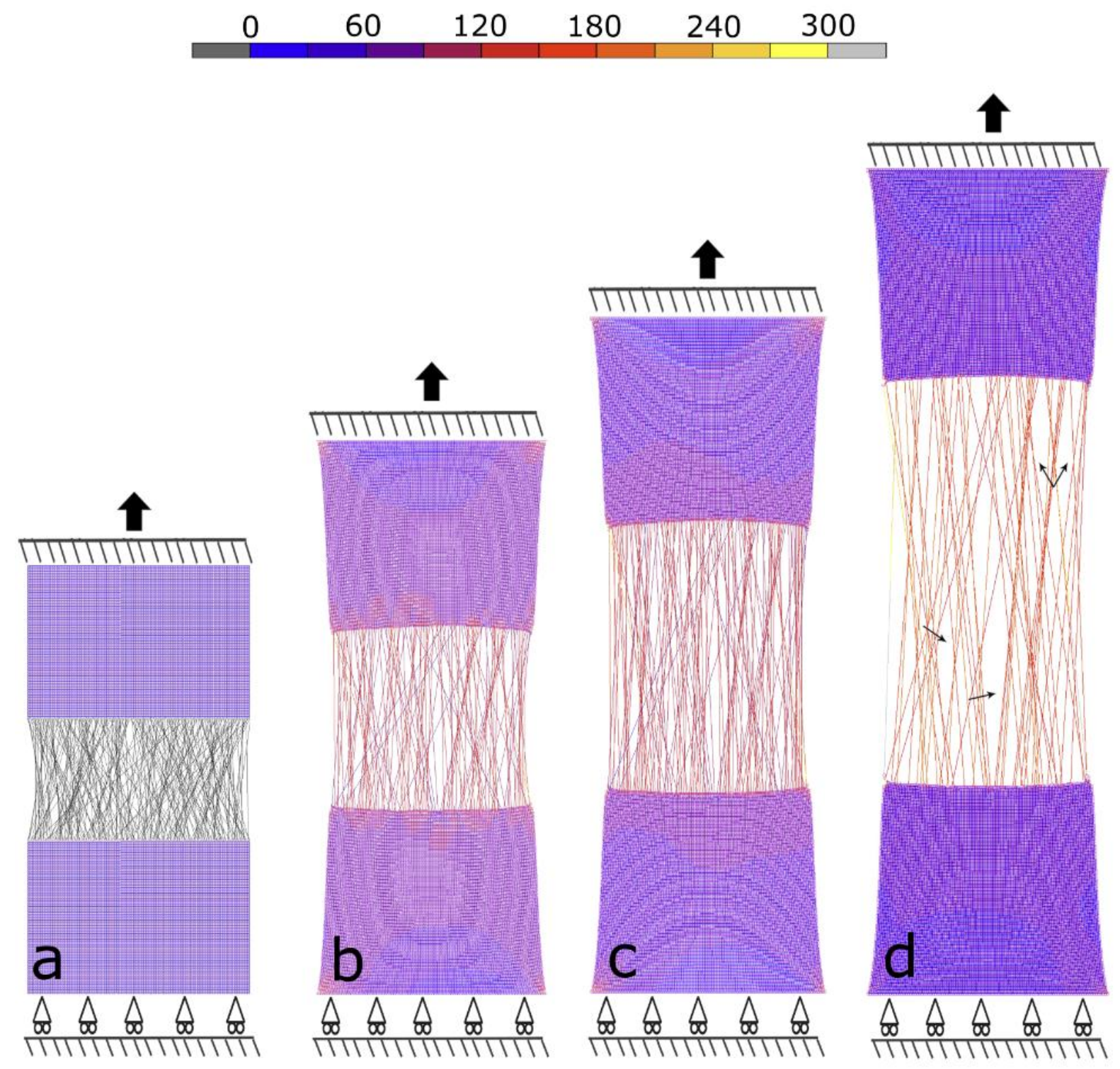

Fig_11 


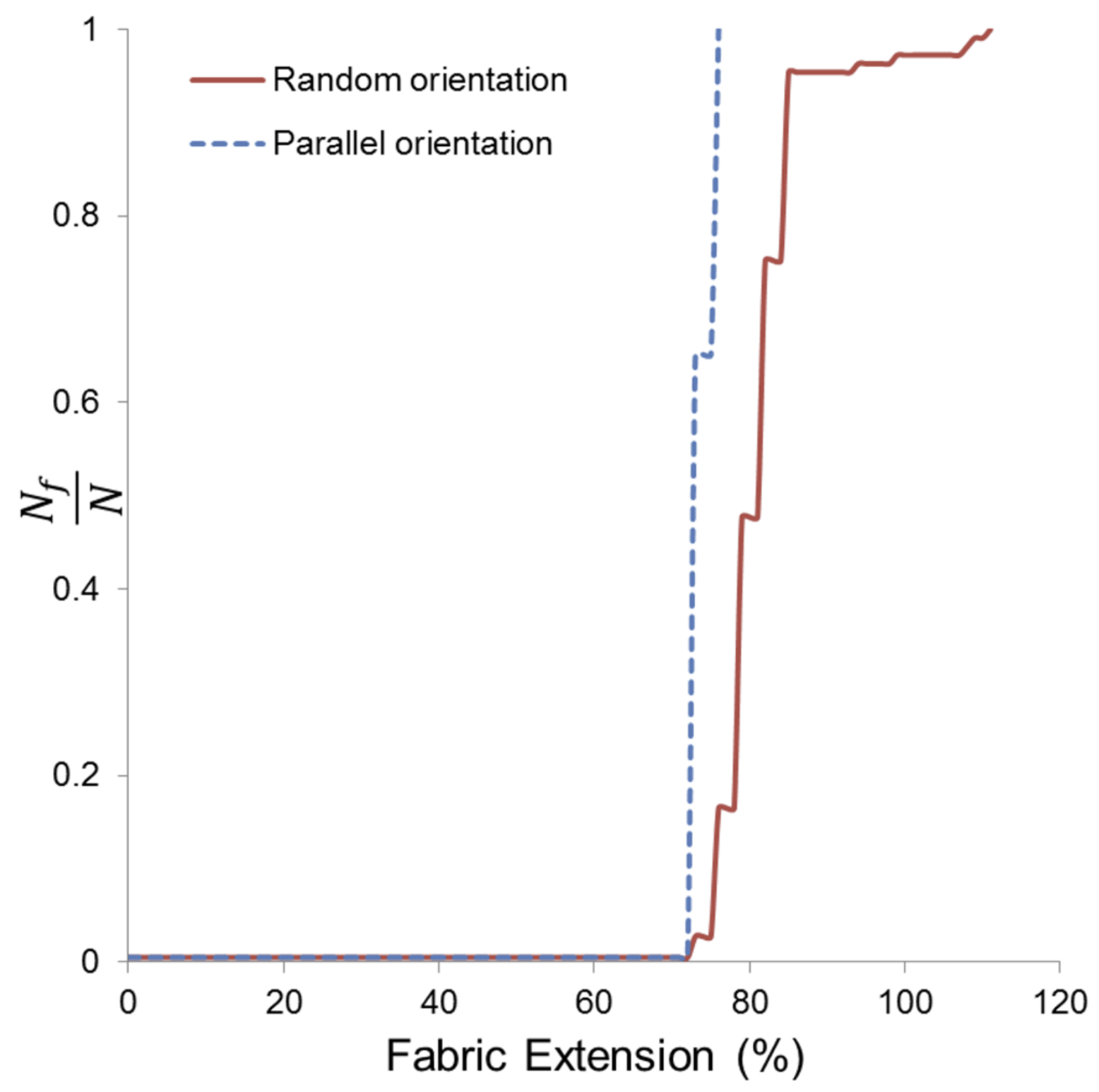

Fig_12 


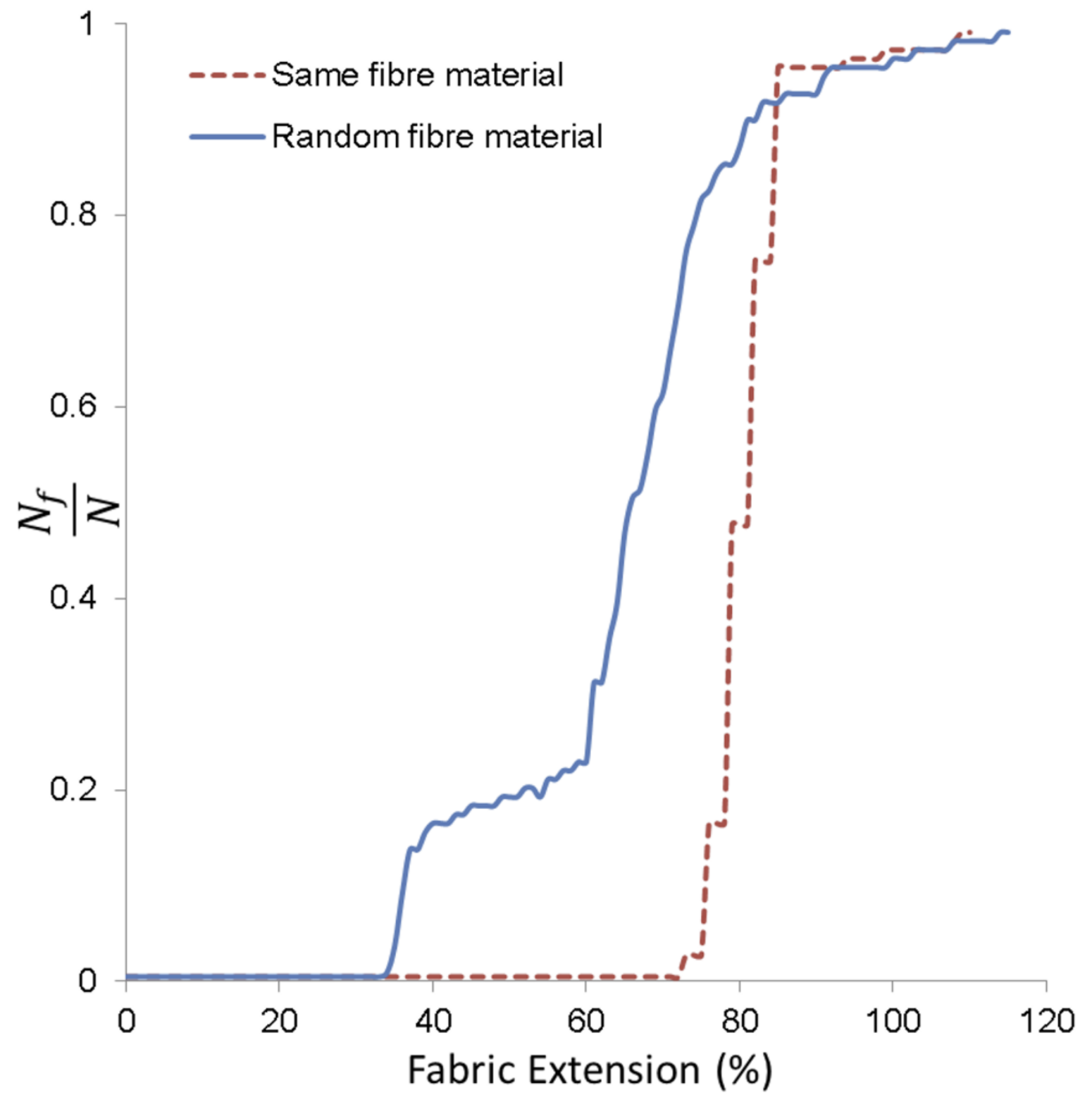

Fig_13 


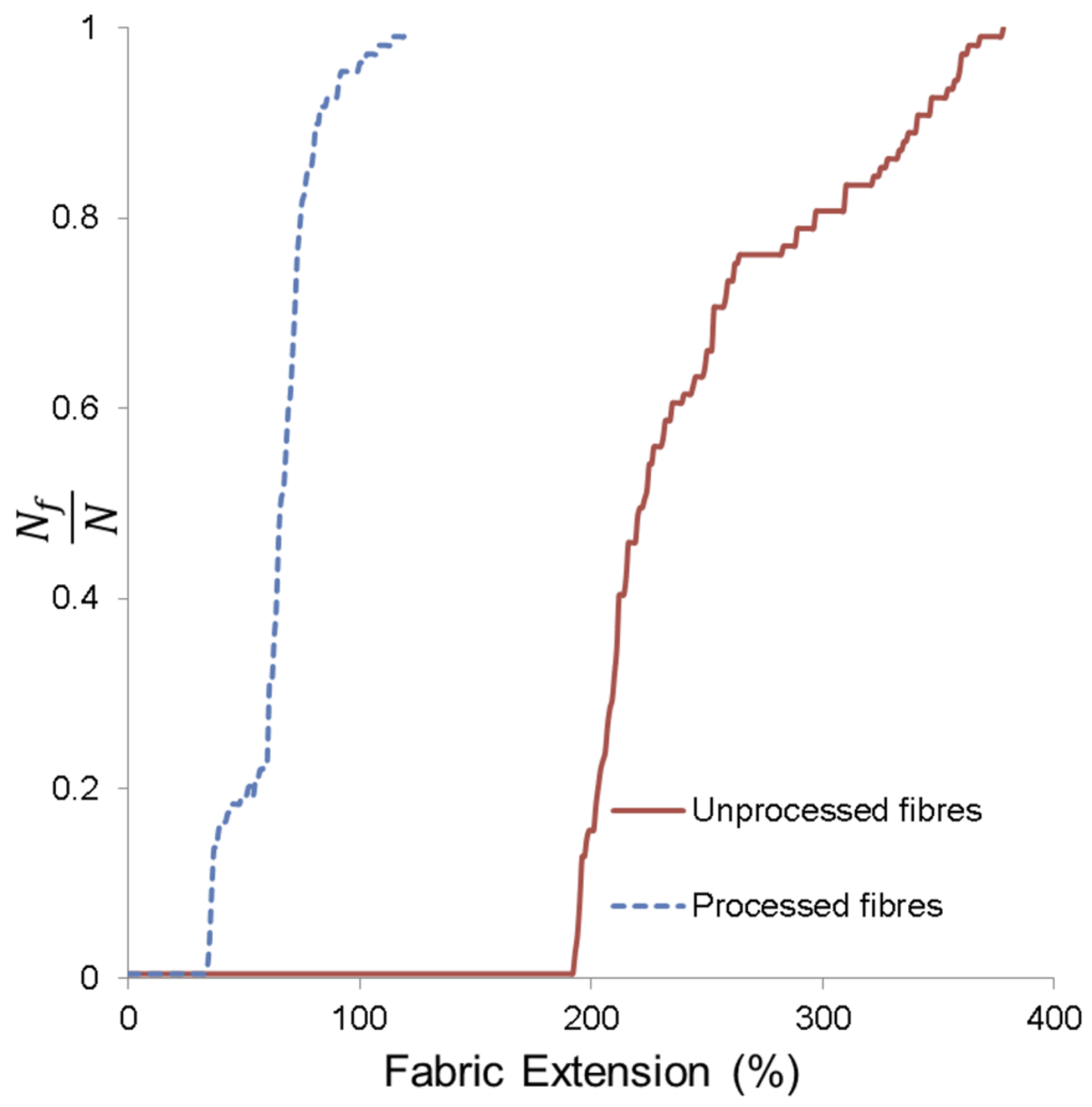

Fig_14 